\title{
Estimating ice phenology on large northern lakes from AMSR-E: algorithm development and application to Great Bear Lake and Great Slave Lake, Canada
}

\author{
K.-K. Kang ${ }^{1,2}$, C. R. Duguay ${ }^{1,2}$, and S. E. L. Howell ${ }^{3}$ \\ ${ }^{1}$ Interdisciplinary Centre on Climate Change (IC3), University of Waterloo, Waterloo, Ontario N2L 3G1, Canada \\ ${ }^{2}$ Department of Geography and Environmental Management, University of Waterloo, Waterloo, Ontario N2L 3G1, Canada \\ ${ }^{3}$ Climate Research Division, Environment Canada, 4905 Dufferin Street, Toronto, Ontario M3H 5T4, Canada
}

Correspondence to: K.-K. Kang (kkkang@uwaterloo.ca)

Received: 9 October 2011 - Published in The Cryosphere Discuss.: 14 November 2011

Revised: 4 February 2012 - Accepted: 23 February 2012 - Published: 8 March 2012

\begin{abstract}
Time series of brightness temperatures $\left(T_{\mathrm{B}}\right)$ from the Advanced Microwave Scanning Radiometer-Earth Observing System (AMSR-E) are examined to determine ice phenology variables on the two largest lakes of northern Canada: Great Bear Lake (GBL) and Great Slave Lake (GSL). $T_{\mathrm{B}}$ measurements from the 18.7, 23.8, 36.5, and $89.0 \mathrm{GHz}$ channels ( $\mathrm{H}-$ and $\mathrm{V}$ - polarization) are compared to assess their potential for detecting freeze-onset/melt-onset and ice-on/ice-off dates on both lakes. The $18.7 \mathrm{GHz}(\mathrm{H}-$ pol) channel is found to be the most suitable for estimating these ice dates as well as the duration of the ice cover and icefree seasons. A new algorithm is proposed using this channel and applied to map all ice phenology variables on GBL and GSL over seven ice seasons (2002-2009). Analysis of the spatio-temporal patterns of each variable at the pixel level reveals that: (1) both freeze-onset and ice-on dates occur on average about one week earlier on GBL than on GSL (Day of Year (DY) 318 and 333 for GBL; DY 328 and 343 for GSL); (2) the freeze-up process or freeze duration (freezeonset to ice-on) takes a slightly longer amount of time on GBL than on GSL (about 1 week on average); (3) melt-onset and ice-off dates occur on average one week and approximately four weeks later, respectively, on GBL (DY 143 and 183 for GBL; DY 135 and 157 for GSL); (4) the break-up process or melt duration (melt-onset to ice-off) lasts on average about three weeks longer on GBL; and (5) ice cover duration estimated from each individual pixel is on average about three weeks longer on GBL compared to its more southern counterpart, GSL. A comparison of dates for several ice phenology variables derived from other satellite remote sensing products (e.g. NOAA Interactive Multisensor Snow and Ice
\end{abstract}

Mapping System (IMS), QuikSCAT, and Canadian Ice Service Database) show that, despite its relatively coarse spatial resolution, AMSR-E $18.7 \mathrm{GHz}$ provides a viable means for monitoring of ice phenology on large northern lakes.

\section{Introduction}

Lake ice cover is an important component of the terrestrial cryosphere for several months of the year in high-latitude regions (Duguay et al., 2003). Lake ice is not only a sensitive indicator of climate variability and change, but it also plays a significant role in energy and water balance at local and regional scales. The presence of an ice cover alters lake-atmosphere exchanges (Duguay et al., 2006; Brown and Duguay, 2010). When energy movement occurs during temperature change, heat transfer (thermodynamics) influences ice thickening as well as the timing and duration of freeze-up and break-up processes, which is referred to as ice phenology (Jeffries and Morris, 2007). Lake ice phenology, which encompasses freeze-onset/melt-onset, ice-on/ice-off dates, and ice cover duration, is largely influenced by air temperature changes and is therefore a robust indicator of climate conditions (e.g. Bonsal et al., 2006; Duguay et al., 2006; Kouraev et al., 2007; Latifovic and Pouliot, 2007; Schertzer et al., 2008; Howell et al., 2009).

The analysis of historical trends (1846-1995) in in situ observations of lake and river ice phenology has provided evidence of later freeze-up (ice-on) and earlier break-up (iceoff) dates at the northern hemispheric scale (Magnuson et al., 2000; Brown and Duguay, 2010). In Canada, from 1951 to 
2000, trends towards earlier ice-off dates have been observed for many lakes, but ice-on dates have shown few significant trends over the same period (Duguay et al., 2006). The observed changes in Canada's lake ice cover have also been found to be influenced by large-scale atmospheric forcings (Bonsal et al., 2006). Canada's government-funded historical ground-based observational network has provided much of the evidence for the documented changes for most of the 20th century and for establishing links with variations in atmospheric teleconnection indices, notably Pacific oscillation patterns such as Pacific North American Pattern and Pacific Decadal Oscillation. Unfortunately, the Canadian groundbased lake ice network has been eroded to the point where it can no longer provide the quantity of observations necessary for climate monitoring across the country. Satellite remote sensing is the most logical means for establishing a global observational network as the reduction in the ground-based lake ice network seen in Canada has been mimicked in many other countries of the Northern Hemisphere (IGOS, 2007).

From a satellite remote sensing perspective, dates associated with estimating the freeze-up process (i.e. onset of freeze until a complete sheet of ice is formed) in autumn and early winter are particularly difficult to determine using optical satellite sensors such as the Moderate Resolution Imaging Spectroradiometer (MODIS) and the Advanced Very High Resolution Radiometer (AVHRR) on high-latitude lakes due to long periods of obscuration by darkness and extensive cloud cover (Maslanik et al., 1987; Jeffries et al., 2005; Latifovic and Pouliot, 2007). QuikSCAT has been used successfully to derive and map freeze-onset, melt-onset and ice-off dates on Great Bear Lake (GBL) and Great Slave Lake (GSL) (Howell et al., 2009). Unfortunately, QuikSCAT data are no longer available for lake ice monitoring on large lakes since its nominal mission ended on 23 November 2009. Previous investigations have shown the utility of observing lake ice phenology variables through the visual interpretation of brightness temperature $\left(T_{\mathrm{B}}\right)$ changes from the Scanning Multichannel Microwave Radiometer (SMMR) at $37 \mathrm{GHz}$ (Barry and Maslanik, 1993) and the Special Sensor Microwave/Imager (SSM/I) at $85 \mathrm{GHz}$ (Walker et al., 1993, 2000) on GSL, but identifying spatial variability in these variables is difficult due to their coarse resolution $(\sim 25 \mathrm{~km})$. In a recent study, SSM/I has been used in combination with radar altimetry to determine automatically ice phenology events on Lake Baikal (Kouraev et al., 2007).

Measurements by the Advanced Microwave Scanning Radiometer-Earth Observing System (AMSR-E) that offer improved spatial resolution have yet to be assessed for monitoring ice phenology. The objectives of this paper are to (i) evaluate the utility of AMSR-E $T_{\mathrm{B}}$ measurements for estimating lake ice phenology, (ii) develop a comprehensive algorithm for mapping lake ice phenology variables, and (iii) apply the algorithm over both GBL and GSL to investigate the spatio-temporal variability of each lakes ice phonology from 2002 to 2009.

\section{Background}

\subsection{Passive microwave radiometry of lake ice}

The discrimination of ice cover characteristics from passive microwave brightness temperature $\left(T_{\mathrm{B}}\right)$ measurements requires a good knowledge of the radiometric properties of ice in nature (Kouraev et al., 2007). In contrast to the highloss characteristics of sea ice (due to salinity), one of the major microwave characteristics of pure freshwater ice is its low-loss transmission behavior (Ulaby et al., 1986). The $T_{\mathrm{B}}$ at passive microwave frequencies is defined as the product of the emissivity $(\varepsilon)$ and physical temperature $\left(T_{\text {kin }}\right)$ of the medium:

$T_{\mathrm{B}}=\varepsilon T_{\text {kin }}$

Passive microwave systems can measure, regardless of cloud coverage and darkness, naturally emitted radiation through $T_{\mathrm{B}}$. Since emissivity ranges between 0 and 1 , the $T_{\mathrm{B}}$ is lower than the kinetic temperature of the medium. The large change in emissivity from open water $(\varepsilon=0.443-$ 0.504 at $24 \mathrm{GHz})$ to ice covered conditions $(\varepsilon=0.858-0.908$ at $24 \mathrm{GHz}$ ) (Hewison and English, 1999; Hewison, 2001) makes the determination of the timing of ice formation and decay on large, deep lakes, feasible from $T_{\mathrm{B}}$ measurements. The emissivity of ice, and therefore $T_{\mathrm{B}}$, further increases from its initial formation as the effect of the radiometrically cold water under the ice cover decreases with ice thickening (Kang et al., 2010).

\subsection{Definitions of ice phenology variables}

The definitions of freeze-up and break-up are opposite: the former describes the time period between the beginning of ice formation and the formation of a complete sheet of ice, while the latter describes the time period between the onset of spring melt and the complete disappearance of ice from the lake surface. Since the algorithm presented herein operates on a pixel-by-pixel basis and is applied over entire lake surfaces, it is important to provide clear definitions of the ice phenology variables as they relate to individual pixels and over whole lakes (or lake sections) (Table 1). At the level of the pixel, the freeze-up period encompasses freeze onset (FO), ice-on and freeze duration (FD), while the break-up period comprises melt onset (MO), ice off and melt duration (MD). The period between ice-on and ice-off covers an ice season and is referred to as ice cover duration (ICDp; $p$ for pixel). At the lake or lake section level (third column of Table 1), complete freeze over (CFO), water clear of ice (WCI) and ice cover duration (ICDe; e for entire lake or lake sections as to avoid land contamination in some AMSR-E $T_{\mathrm{B}}$ measurements) are the terms used from here onward. CFO corresponds to the date when all pixels within the lake or lake section have become ice-covered (i.e. all flagged with having ice-on). WCI corresponds to the date when all pixels have 
Table 1. Definition of ice phenology variables at per pixel level and for entire lake or lake section.

\begin{tabular}{|c|c|c|}
\hline & Pixel level & Entire lake or lake section \\
\hline $\begin{array}{l}\text { Freeze-up } \\
\text { Period }\end{array}$ & $\begin{array}{l}\text { Freeze onset (FO): First day of the year on which the } \\
\text { presence of ice is detected in a pixel and remains until } \\
\text { ice-on } \\
\text { Ice-on: Day of the year on which a pixel becomes } \\
\text { totally ice-covered } \\
\text { Freeze duration (FD): number of days between } \\
\text { freeze-onset and ice-on dates }\end{array}$ & $\begin{array}{l}\text { Complete freeze over }(\mathrm{CFO}) \text { : } \\
\text { Day of the year when all pixels become totally ice- } \\
\text { covered }\end{array}$ \\
\hline $\begin{array}{l}\text { Break-up } \\
\text { period }\end{array}$ & $\begin{array}{l}\text { Melt onset (MO): First day of the year on which gen- } \\
\text { eralized spring melt begins in a pixel } \\
\text { Ice-off: Day of the year on which a pixel becomes } \\
\text { totally ice-free } \\
\text { Melt duration (MD): numbers of days between melt- } \\
\text { onset and ice-off dates }\end{array}$ & $\begin{array}{l}\text { Water clear of ice }(\mathrm{WCI}) \text { : } \\
\text { Day of the year when all pixels become totally ice- } \\
\text { free }\end{array}$ \\
\hline Ice season & $\begin{array}{l}\text { Ice cover duration (ICDp): number of days between } \\
\text { ice-on and ice-off dates }\end{array}$ & $\begin{array}{l}\text { Ice cover duration (ICDe): number of days between } \\
\text { CFO and WCI }\end{array}$ \\
\hline
\end{tabular}

become ice-free (i.e. all flagged with having ice-off). While ICDp is calculated for each individual pixel from dates of ice-on to ice-off, ICDe is determined as the number of days between CFO and WCI within an ice season.

\section{Study area}

GBL and GSL are two of the largest freshwater lakes in the world. Located in the Mackenzie River Basin they fall within two physiographic regions of Canada's Northwest Territories: the Precambrian Shield and the Interior Plains (Fig. 1). The eastern parts of both lakes are situated in the Precambrian Shield. Its undulating topography with bedrock outcrops causes the formation of rounded hills and valleys. The high topography of the western Cordillera and low relief of the central and eastern parts of the Mackenzie Basin strongly influence the regional climate (e.g. atmospheric circulation pattern and the advective heat and moisture fluxes) (Woo et al., 2008). Most of GBL and the western/central parts of GSL are located in the flat-lying Interior Plains and underlain by thick glacial, fluvial, and lacustrine deposits; in addition, the Plains are dotted with numerous wetlands and lakes (Woo et al., 2008). GBL and GSL lie between $60^{\circ}$ to $67^{\circ} \mathrm{N}$ and between $109^{\circ}$ to $126^{\circ} \mathrm{W}$ (Fig. 1), and, respectively, have surface areas of $31.3 \times 10^{3} \mathrm{~km}^{2}$ and $28.6 \times 10^{3} \mathrm{~km}^{2}$, and average depths of $76 \mathrm{~m}$ and $88 \mathrm{~m}$ (Rouse et al., 2008a; Woo et al., 2008). The northern extent of GBL is influenced by colder temperatures than its more southern counterpart (Rouse et al., 2008b).

From 2002 to 2009, the period of analysis of this study, the average air temperature recorded at the Deline weather station $\left(65^{\circ} 12^{\prime} \mathrm{N}, 123^{\circ} 26^{\prime} \mathrm{W}\right)$, near the western shore of GBL, ranged between $-25.4^{\circ} \mathrm{C}$ and $-20.6^{\circ} \mathrm{C}$ for winter (DJF) and

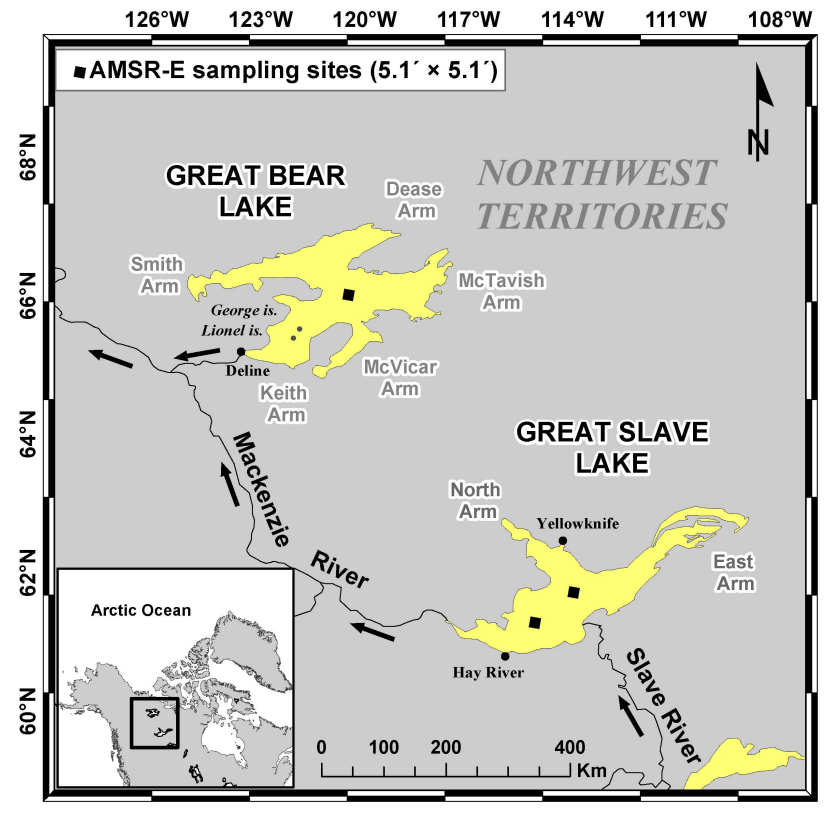

Fig. 1. Map showing location of Great Bear Lake (GBL) and Great Slave Lake (GSL), and their meteorological stations (Deline, Yellowknife, and Hay River) within the Mackenzie River Basin. Solid squares represent $5.1^{\prime} \times 5.1^{\prime}(9.48 \mathrm{~km} \times 9.48 \mathrm{~km})$ of sampling sites at $18.7 \mathrm{GHz}$ for the development of the ice phenology algorithm. Arrows indicate river flow direction.

from $10.0^{\circ} \mathrm{C}$ to $12.1^{\circ} \mathrm{C}$ for summer (JJA) with $20.2 \mathrm{~cm}$ of average annual snowfall (Table 2). For GBL, complete water turnover occurs at least in some parts of the lake and no break-up occurs until early July (Rouse et al., 2008a).

GSL is part of the north-flowing river system in the Mackenzie Basin (Rouse et al., 2008b). Situated at a more 
Table 2. Seasonal mean air temperature $\left(6^{\circ} \mathrm{C}\right)$ for winter (DJF), spring (MAM), summer (JJA) and autumn (SON), and annual snowfall (cm) recorded at Deline (GBL), Yellowknife and Hay River combined (GSL) meteorological stations (2002-2009). M indicates missing data. S.D. is standard deviation.

\begin{tabular}{llllllllllllll}
\hline & \multicolumn{3}{c}{ DJF } & \multicolumn{2}{c}{ MAM } & \multicolumn{2}{c}{ JJA } & \multicolumn{2}{c}{ SON } & \multicolumn{2}{c}{ Annual temp } & \multicolumn{2}{c}{ Annual snowfall (cm) } \\
\cline { 2 - 13 } & GBL & GSL & GBL & GSL & GBL & GSL & GBL & GSL & GBL & GSL & GBL & GSL \\
\hline 2002 & -23.9 & -21.5 & -10.6 & -9.5 & 11.1 & 14.2 & -3.1 & -1.3 & -6.0 & -4.0 & 14.6 & 15.5 \\
2003 & -22.1 & -20.6 & -8.2 & -4.3 & 11.6 & 14.7 & -3.8 & -0.3 & -6.1 & -2.9 & 22.2 & 16.2 \\
2004 & -24.4 & -21.0 & -11.7 & -7.6 & 10.4 & 13.8 & -6.9 & -2.9 & -8.7 & -5.1 & 16.1 & 16.9 \\
2005 & -24.7 & -22.9 & -6.0 & -3.6 & 10.0 & 13.6 & -5.4 & 0.0 & -5.6 & -2.1 & 25.7 & 24.1 \\
2006 & -20.6 & -15.9 & -7.8 & -1.0 & 12.1 & 15.9 & -4.9 & -2.0 & -5.5 & -0.9 & 28.8 & 24.0 \\
2007 & -22.7 & -18.7 & -9.7 & -4.7 & 11.2 & 14.6 & -5.3 & -1.6 & -7.0 & -3.3 & 17.0 & 19.7 \\
2008 & -25.0 & -23.5 & -8.2 & -6.0 & 10.6 & 15.4 & -4.7 & 0.0 & -7.2 & -3.9 & 16.7 & 26.9 \\
2009 & -25.4 & -23.8 & -10.4 & -7.1 & 10.7 & 14.2 & -4.5 & 0.1 & -7.1 & -3.7 & M & 22.2 \\
Avg & -23.5 & -21.8 & -8.6 & -4.9 & 11.4 & 14.5 & -4.6 & -1.6 & -6.3 & -3.4 & 20.2 & 20.7 \\
S.D. & 1.5 & 2.9 & 2.0 & 2.2 & 0.8 & 0.9 & 1.5 & 1.7 & 1.1 & 1.3 & 5.5 & 4.2 \\
\hline
\end{tabular}

southern location, the mean air temperature in the GSL area is generally warmer than that of GBL, and therefore the GSL open-water period is about four to six weeks longer than it is at GBL (Rouse et al., 2008b; Schertzer et al., 2008). GSL is ice-free from the beginning of June until mid- to late-December; however, the ice conditions vary significantly from year to year on this lake (Blanken et al., 2008). The high spatiotemporal variability in air temperature and wind speed over GSL influences the surface water temperature and lake heat flux (Rouse et al., 2008b; Schertzer et al., 2008). From 2002 to 2009 , the mean air temperature in winter ranged from $-23.8^{\circ} \mathrm{C}$ to $-15.9^{\circ} \mathrm{C}$ and between $13.6^{\circ} \mathrm{C}$ and $15.9^{\circ} \mathrm{C}$ in summer, with $20.7 \mathrm{~cm}$ of average annual snowfall (Table 2). Spring and autumn temperatures, which mark the beginning of the break-up and freeze-up periods, respectively, in the GSL region $\left(-9.5^{\circ} \mathrm{C}\right.$ to $-1.0^{\circ} \mathrm{C} ;-2.9^{\circ} \mathrm{C}$ to $\left.0.1^{\circ} \mathrm{C}\right)$ are higher than near GBL $\left(-11.7^{\circ} \mathrm{C}\right.$ to $-6.0^{\circ} \mathrm{C} ;-6.9^{\circ} \mathrm{C}$ to $-3.1^{\circ} \mathrm{C}$ ) due to the latitudinal difference between the two lakes.

\section{Data}

Two data sets were used in this study. Primary data correspond to those utilized to examine the sensitivity of passive microwave $T_{\mathrm{B}}$ measurements at various frequencies and to develop the ice phenology algorithm. They consist of meteorological station (air temperature) and AMSR-E data. The secondary, auxiliary, data correspond to ice products or images from other sources. They are used for comparison with the AMSR-E derived ice phenology variables.

\subsection{Primary data}

\subsubsection{AMSR-E}

AMSR-E $T_{\mathrm{B}}$ data were obtained for the period 2002-2009. AMSR-E (fixed incident angle: 54.8 degree) is a conically scanning, twelve-channel passive microwave radiometer system, measuring horizontally and vertically polarized microwave radiation from $6.9 \mathrm{GHz}$ to $89.0 \mathrm{GHz}$ (Kelly, 2009). The instantaneous field-of-view for each channel varies from 76 by $44 \mathrm{~km}$ at $6.9 \mathrm{GHz}$ to 6 by $4 \mathrm{~km}$ at $89.0 \mathrm{GHz}$, and the along-track and cross-track sampling interval of each channel is $10 \mathrm{~km}(5 \mathrm{~km}$ sampling interval in $89.0 \mathrm{GHz})$. In this study, the AMSR-E/Aqua L2A global swath spatially raw brightness temperature product (AE_L2A) was used.

$T_{\mathrm{B}}$ at $18.7,23.8$, and $36.5 \mathrm{GHz}$ AMSR-E observations for each day falling within a $5.1^{\prime} \times 5.1^{\prime}$ grid for both descending and ascending overpasses were averaged over the areas of interest, within the central sections of GBL $\left(66^{\circ} \mathrm{N}\right.$, $\left.120^{\circ} 30^{\prime} \mathrm{W}\right)$ and GSL $\left(61^{\circ} 19.8^{\prime} \mathrm{N}, 115^{\circ} \mathrm{W}\right.$ and $61^{\circ} 41.8^{\prime} \mathrm{N}$, $113^{\circ} 49.5^{\prime} \mathrm{W}$ ) (Fig. 1). The $6.9 \mathrm{GHz}$ and $10.7 \mathrm{GHz}$ channels were not considered, as they are more subject to land contamination from lakeshores due to their larger footprint. The divide-and-conquer method for a Delaunay triangulation and inverse distance weighted linear interpolation were applied to the L2A data because the $T_{\mathrm{B}} \mathrm{S}$ in ascending and descending modes did not have matching geographic positions over GBL and GSL due to different orbit overpasses. The sampling intervals at all frequency bands are spaced every $10 \mathrm{~km}(5 \mathrm{~km}$ at $89.0 \mathrm{GHz}$ ) along and across track in AMSR-E L2A products (Kelly, 2009). Therefore, we chose $10 \mathrm{~km}$ grid spacing for the linear interpolation, except for $89 \mathrm{GHz}$, for which we chose a $5 \mathrm{~km}$ grid spacing. 


\subsubsection{Meteorological station data}

Meteorological data from the National Climate Data and Information Archive of Environment Canada (http://climate. weatheroffice.ec.gc.ca/climateData/canada_e.html) were acquired from three stations located in the vicinity of GBL and GSL. The stations selected include Deline (YWJ, $65^{\circ} 12^{\prime} \mathrm{N}$, $123^{\circ} 26^{\prime} \mathrm{W}$ ) to provide climate information on GBL, and Yellowknife (YZF, $62^{\circ} 27.6^{\prime} \mathrm{N}, 114^{\circ} 26.4^{\prime} \mathrm{W}$ ) and Hay River (YHY, $60^{\circ} 50.4^{\prime} \mathrm{N}, 115^{\circ} 46.8^{\prime} \mathrm{W}$ ) to characterize the climate in the GSL area (Fig. 1). Time series of maximum and mean air temperatures from 2002 to 2009 were used for comparison with AMSR-E $T_{\mathrm{B}}$ measurements as supporting data for the development of the ice phenology algorithm.

\subsection{Auxiliary data}

Auxiliary data used for comparison with AMSR-E derived ice phenology variables consisted of NOAA Interactive Multisensor Snow and Ice Mapping System (NOAA/IMS) ice products, weekly ice observations from the Canadian Ice Service (CIS) during freeze-up and break-up period, and MODIS images acquired during the break-up period (not examined during freeze-up due to polar darkness). FO, MO, and ice-off dates derived from the QuikSCAT Scatterometer Image Reconstruction eggs product at the pixel scale by Howell et al. (2009) are compared with the same ice phenology variables derived from AMSR-E for the period 20022006.

The NOAA/IMS (http://www.natice.noaa.gov/ims/) $24 \mathrm{~km}$ and $4 \mathrm{~km}$ resolution grid products (Helfrich et al., 2007) were also available for comparison. The IMS $4 \mathrm{~km}$ product is available since 2004. Ice-on and ice-off dates (binary value: ice vs open water) at the pixel level as well as CFO dates (all pixels coded as ice) and WCI dates (all pixels coded as open water) on both GBL and GSL were derived for the period 2004-2009. The $4 \mathrm{~km}$ IMS product was used for comparison with AMSR-E derived ice phenology events.

CIS weekly observations of GBL and GSL ice cover were obtained from 2002-2009. Analysts at the CIS determine a single lake-wide ice fraction value in tenths ranging from 0 (open water) to 10 (complete ice cover) every Friday from the visual interpretation of NOAA AVHRR (1 km pixels) and Radarsat ScanSAR images ( $100 \mathrm{~m}$ pixels) compiled over a full week for many lakes across Canada, including GBL and GSL. CFO and WCI dates can be derived from this product with about a one-week accuracy. CFO was determined as the date when the ice fraction changes from 9 to 10 and remains at this value for the winter period, while WCI was determined as the date when the lake-ice fraction passes from 1 to 0 . Lake-wide CFO and WCI dates were derived for all ice seasons corresponding to the AMSR-E (2002-2009) observations.

Finally, MODIS quick-look images of GBL and GSL (2002-2009) were downloaded from the Geographic
Information Network of Alaska (http://www.gina.alaska. edu) for general visual comparison with AMSR-E derived ice products during spring break-up. No suitable images were available during fall freeze-up due to long periods of extensive cloud cover and polar darkness. The MODIS quick-look images are provided as true-color composites (Bands 1, 4, 3 in RGB) - Band 1 (250 m, 620-670 nm), Band 4 (500 m, $545-565 \mathrm{~nm}$ ), and Band 3 (500 m, 459-479 nm).

\section{Ice phenology algorithm}

\subsection{Examination of $T_{\mathrm{B}}$ evolution during ice-cover and ice-free seasons}

The development of a new algorithm for determining various ice phenology variables through ice seasons required the seasonal evolution of horizontally and vertically polarized $T_{\mathrm{B}}$ at different frequencies be examined first. The sensitivity of $T_{\mathrm{B}}$ at $18.7,23.8,36.5$, and $89 \mathrm{GHz}$ to ice phenology was examined by selecting one pixel located in the central section of GBL $\left(66^{\circ} \mathrm{N}, 120^{\circ} 30^{\prime} \mathrm{W}\right)$ and two in the main basin of GSL $\left(61^{\circ} 19.8^{\prime} \mathrm{N}, 115^{\circ} \mathrm{W}\right.$ and $\left.61^{\circ} 41.8^{\prime} \mathrm{N}, 113^{\circ} 49.5^{\prime} \mathrm{W}\right)$ (see Fig. 1). Air temperature data from the meteorological stations were used in support of the analysis of the temporal evolution of the AMSR-E $T_{\mathrm{B}}$ to detect ice phenology events during the freeze-up and break-up periods at the three sampling sites (pixels) that could then guide the development of the ice phenology algorithm. Although the temporal evolution was examined at the three sites and for all years (20022009), for sake of brevity, one site on GBL from 2003-2004 is used to illustrate the general sensitivity of $T_{\mathrm{B}}$ during the freeze-up and break-up periods (Fig. 2). Changes in $T_{\mathrm{B}}$ are interpreted separately below for the freeze-up and the breakup periods.

\subsubsection{Freeze-up period}

Using the sampling site on GBL as an example (see Fig. 1), when surface air temperature falls below the freezing point (Fig. 2), the expected increase in $T_{\mathrm{B}}$ with the onset of ice cover formation lags due to the large heat capacity causing delayed ice formation of GBL. This is also observed over GSL (not shown). As shown in Fig. 2, it takes about four to six weeks for the central part of GBL to show the beginning of the freeze-up process. $T_{\mathrm{B}}$ then starts to increase rapidly in association with an increase in fractional ice coverage (FO to ice-on). The distinct increase of $T_{\mathrm{B}}$ is more strongly apparent at horizontal polarization (Fig. 2, upper) for which $T_{\mathrm{B}}$ increases by approximately $70-80 \mathrm{~K}$ from open water (ice-free season) to ice-on conditions, compared to vertical polarization (Fig. 2, middle) for each frequency.

From the ice-on date near mid-December to the onset of melt (MO), the increase in $T_{\mathrm{B}}$ is due to ice growth and thickening until lake ice reaches its maximum thickness around mid-April. An increase in $T_{\mathrm{B}}$ is expected during the 


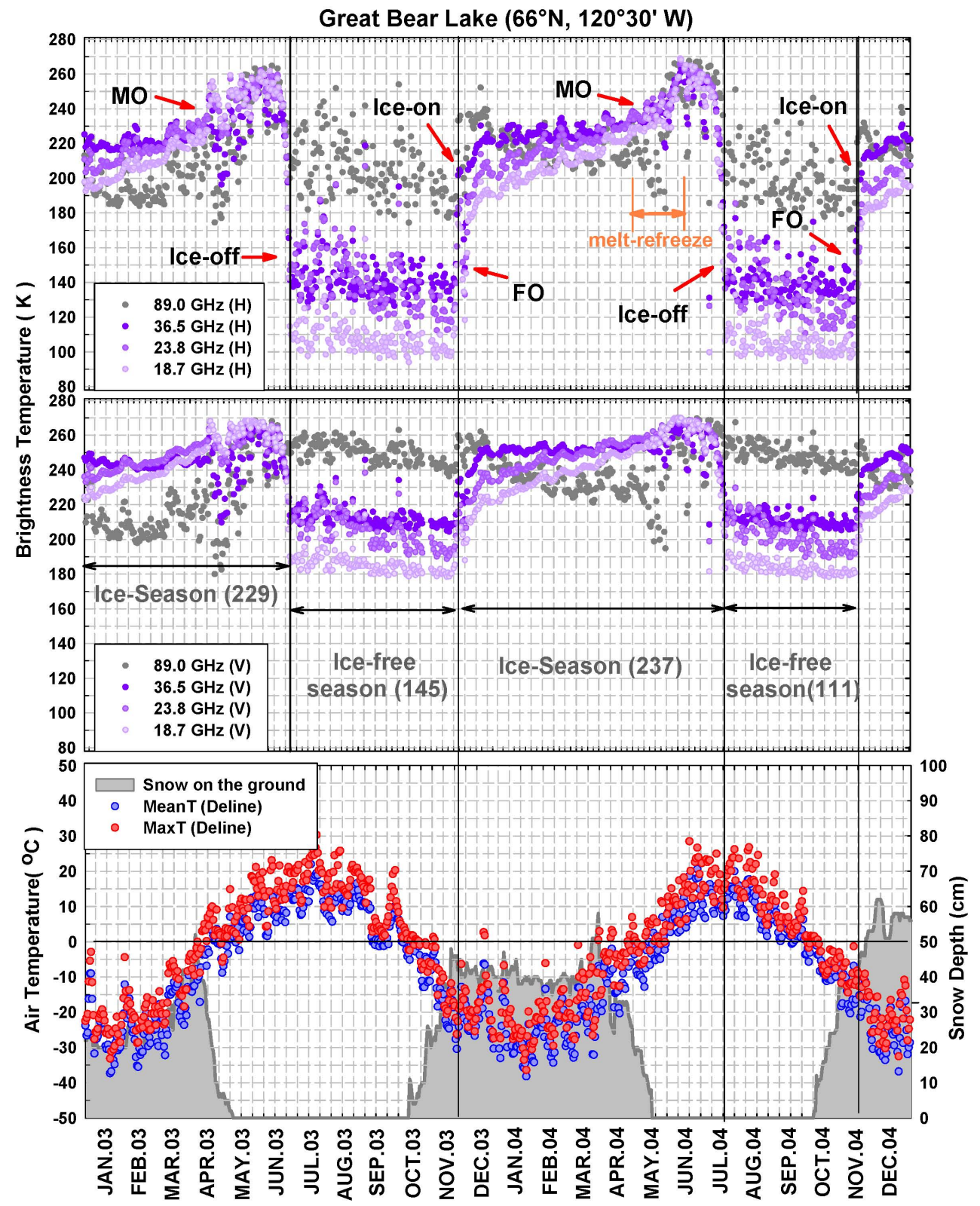

Fig. 2. Temporal evolution of horizontal (top) and vertical (middle) polarized brightness temperature at 18.7 (light violet), 23.8 (middle violet), 36.5 (dark violet), 89.0 (dark grey) GHz (2003-2004) for sampling site on GBL (see Fig. 1). The time series of maximum (Max_T, red) and mean (Mean_T, blue) air temperatures obtained at Deline meteorological station is shown in the bottom panel of the figure, with snow depth as grey shaded area. Numbers after both "Ice Season" and "Ice-free Season" indicate number of days.

ice growth season since thicker ice reduces the influence of the lower emissivity (radiometrically cold) liquid water below the ice (Kang et al., 2010). The slope (rate of change) of $T_{\mathrm{B}}$ with time is steeper at $18.7 \mathrm{GHz}$ than at $23.8,36.5$ and $89 \mathrm{GHz}$ during ice growth due to greater penetration depth at lower frequencies. The rate of increase in $T_{\mathrm{B}}$ with ice thickening slows down more quickly at the higher frequencies as the ice becomes thicker (Fig. 2). The oscillating behavior of $T_{\mathrm{B}}$ at $\mathrm{H}$-pol and V-pol during the ice growth period depends greatly on the imaginary part of the index of refraction of ice (Chang et al., 1997; Kang et al., 2010). Differences in $T_{\mathrm{B}}$ among different frequencies are negligible once the lake ice/snow on ice surface becomes wet during warm winter episodes and starting with MO. 


\subsubsection{Break-up period}

Once the mean air temperature begins to exceed $0^{\circ} \mathrm{C}, T_{\mathrm{B}}$ increases rapidly as a result of the higher air temperature and increasing shortwave radiation absorption (decreasing albedo) at the ice/snow surface signalling the start of MO. The wetter the snow cover becomes, the more the observed $T_{\mathrm{B}}$ also increases due to snow's high emissivity during the break-up period (Jeffries et al., 2005).As shown in Fig. 2, during the break-up period on GBL, melt-refreeze events lead to fluctuations in $T_{\mathrm{B}}$ at $18.7-89 \mathrm{GHz}$ along the general spring melt trajectory starting with MO. A similar pattern is noticeable from $T_{\mathrm{B}}$ values analyzed over GSL (not shown). The existence of clear ice causes a rapid break-up process, resulting in decreasing $T_{\mathrm{B}}$. First snow, then snow ice (if any), and finally black ice melt sequentially; the $\mathrm{H}$-pol and V-pol $T_{\mathrm{B}}$ drop rapidly until the ice-off date (Fig. 2). The definition of black ice (or clear ice) and snow ice are described in Kang et al. (2010). During the middle of July, $T_{\mathrm{B}}$, which is affected by the radiometrically cold (low emissivity) freshwater, significantly decreases by about $100-140 \mathrm{~K}$ from ice-covered to ice-free (open water) conditions.

\subsection{Justification of choice of frequency and polarization for algorithm}

Based on the overall examination of the evolution of $T_{\mathrm{B}}$ during the ice and ice-free seasons on GBL and GSL at different frequencies and polarizations, $18.7 \mathrm{GHz} \mathrm{H}$-pol measurements appear to be the most suitable for the development of an ice phenology algorithm. Although H-pol is more sensitive than V-pol to wind-induced open water surface roughness, it also shows a larger rise in $T_{\mathrm{B}}$ from open water to ice cover during the later freeze-up and earlier break-up periods. Thus, it is easier to determine $T_{\mathrm{B}}$ thresholds (described in the section below) related to ice phenology variables at $\mathrm{H}$-pol than at V-pol during those periods. Second, $89 \mathrm{GHz}$ is known to be more sensitive to atmospheric contamination (Kelly, 2009) and is also strongly affected by open water surface roughness from wind, particularly at $\mathrm{H}$-pol. This later effect is also apparent at 23.8 and $36.5 \mathrm{GHz}$. Occasionally high $T_{\mathrm{B}}$ values at 23.8 and $36.5 \mathrm{GHz}$ during the open water season make it difficult to detect the timing of FO and ice-off dates. Although $89.0 \mathrm{GHz}(3.5 \times 5.9 \mathrm{~km})$ from AMSR-E can be good for estimating sea ice concentration due to its finer spatial resolution, AMSR-E $18.7 \mathrm{GHz}$ is better for defining ice phenology variables such as freeze-onset and melt-onset because this frequency has longer penetration depth, allowing less lake ice surface scattering. In addition, brightness temperatures $\left(T_{\mathrm{B}}\right)$ at $89.0 \mathrm{GHz}$ are much more sensitive to surface roughness induced by winds during the open water period compared to the lower frequency channels. As clearly shown in Fig. 2, variations in $T_{\mathrm{B}}$ at $89 \mathrm{GHz}$ are large during this period. This makes the estimation of FO and ice-off dates, in particular, difficult with the thresholding approach

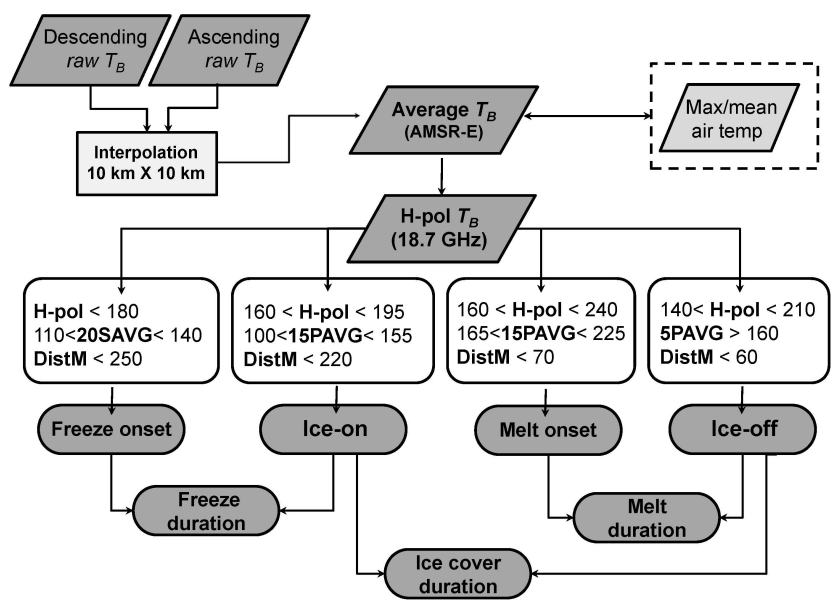

Fig. 3. Flowchart of ice phenology algorithm based on AMSRE $18.7 \mathrm{GHz}$ horizontal polarization $(\mathrm{H}-\mathrm{pol})$ brightness temperature $\left(T_{\mathrm{B}}\right)$. All threshold values are explained in Sect. 5.3.

presented in this paper. Overall, $18.7 \mathrm{GHz} \mathrm{H}$-pol shows less limitations for detecting a broader range of ice phenology variables (FO, ice-on, MO, and ice-off) than the other channels.

\subsection{Determining thresholds for retrieval of ice phenology variables}

A flowchart showing the processing steps for determining the ice phenology variables is given in Fig. 3. Based on the analysis of $T_{\mathrm{B}}$ values at the three test sites on GBL/GSL over seven ice seasons, a suite of criteria (minimum and maximum thresholds, averages of preceding and succeeding days, and threshold value of number of days to the maximum $T_{\mathrm{B}}$ in the time series, DistM) was devised to detect FO, ice-on, $\mathrm{MO}$, and ice-off dates.

\subsubsection{Freeze-up period}

The FO date is detected during the upturn of $T_{\mathrm{B}}$ from an open water surface. A maximum $T_{\mathrm{B}}$ threshold value of $180 \mathrm{~K}$ is high enough to avoid confusion with fluctuating $T_{\mathrm{B}}$ values influenced by wind-induced roughness of the open water surface. Then, in order to discriminate $T_{\mathrm{B}}$ under open water conditions from the starting point of FO, the average taken from the succeeding twenty days for each individual day of the time series is calculated. This average value must fall within the range of $110 \mathrm{~K}$ and $140 \mathrm{~K}$. The last criterion consists of finding the maximum $T_{\mathrm{B}}$ value in the time series, which is reached late during the ice season. Once found, the number of days from each day to that of the maximum $T_{\mathrm{B}}$ (DistM in Fig. 3) is calculated. DistM must be less than 250 days, in addition to falling within the threshold $T_{\mathrm{B}}$ values given above, for the algorithm to be able to detect FO. For detecting the ice-on date, first maximum and minimum threshold values 

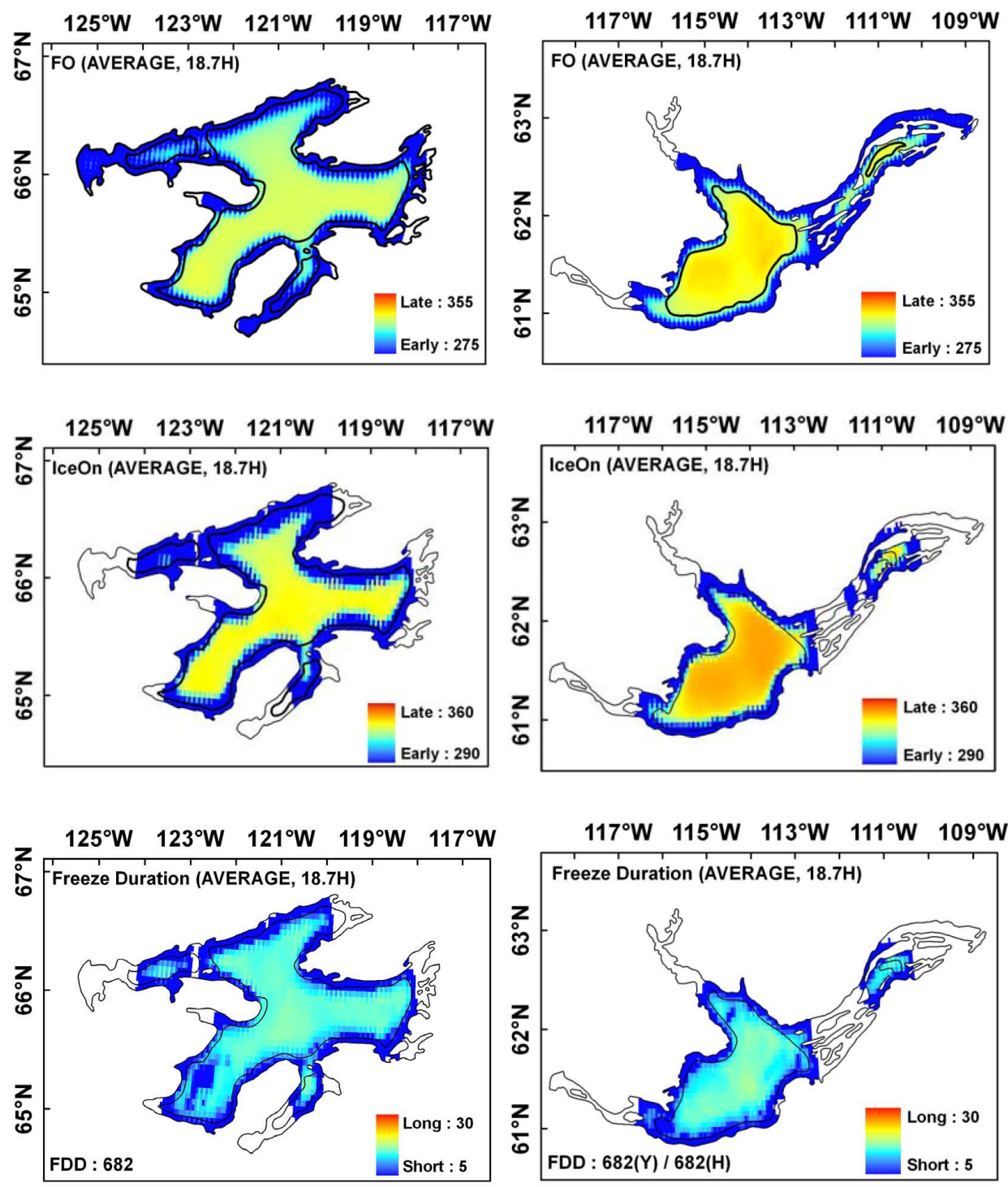

Fig. 4. Freeze-onset (FO), ice-on, and freeze-duration on average (2002-2009) for GBL (left panel) and GSL (right panel). Legend is day of year.

of $195 \mathrm{~K}$ and $160 \mathrm{~K}$ are used. Then, as an extra criterion to distinguish between the FO date and ice-on date, the average $T_{\mathrm{B}}$ value of the 15 days preceding each individual day in the time series has to fall between 100 and $155 \mathrm{~K}$. Lastly, DistM must be less than 220 days.

\subsubsection{Break-up period}

For the determination of the MO date, maximum and minimum threshold values are set to $240 \mathrm{~K}$ and $160 \mathrm{~K}$. Then, for discriminating the starting point of $\mathrm{MO}$ from other days during the ice growth/thickening season, the average $T_{\mathrm{B}}$ calculated from the previous fifteen days of each individual day in the time series must fall between $165 \mathrm{~K}$ and $225 \mathrm{~K}$ threshold and with a DistM of less than 70 days. The ice-off date is detected from a sharp drop in $T_{\mathrm{B}}$ from that of the melt period that starts with $\mathrm{MO}$ (Fig. 2). For this last phenology variable, the maximum and minimum thresholds are set to $140 \mathrm{~K}$ and $210 \mathrm{~K}$. To ensure discrimination of this first day of the icefree season from those of later days, the average $T_{\mathrm{B}}$ value of the preceding five days is fixed to $160 \mathrm{~K}$ and with DistM less than 60 days. 
Table 3. Summary of ice phenology variables during the freeze-up period (average day of freeze-onset (FO) and ice-on, and number of days of freeze duration (FD)) for GBL and GSL (2002-2009). Values within confidence regions in bold. Standard deviation in parentheses.

\begin{tabular}{lllllll}
\hline \multirow{2}{*}{ Year } & \multicolumn{2}{c}{ FO } & \multicolumn{2}{c}{ Ice-On } & \multicolumn{2}{c}{ FD } \\
\cline { 2 - 7 } & GBL & GSL & GBL & GSL & GBL & GSL \\
\hline 2002-2003 & $311 / \mathbf{3 2 0}(14 / 7)$ & $318 / \mathbf{3 3 1}(18 / \mathbf{4})$ & $328 / \mathbf{3 3 3}(11 / 7)$ & $334 / \mathbf{3 4 5}(17 / 7)$ & $32 / \mathbf{2 8}(11 / \mathbf{5})$ & $31 / \mathbf{1 9}(17 / \mathbf{1 0})$ \\
$2003-2004$ & $313 / \mathbf{3 2 2}(11 / \mathbf{5})$ & $319 / \mathbf{3 2 9}(14 / \mathbf{5})$ & $332 / 337(8 / \mathbf{5})$ & $338 / \mathbf{3 4 5}(11 / \mathbf{5})$ & $31 / \mathbf{2 8}(7 / \mathbf{5})$ & $27 / \mathbf{1 5}(15 / 7)$ \\
$2004-2005$ & $303 / \mathbf{3 0 8}(9 / \mathbf{4})$ & $313 / \mathbf{3 2 2}(13 / \mathbf{3})$ & $321 / \mathbf{3 2 3}(6 / \mathbf{4})$ & $331 / \mathbf{3 3 8}(12 / \mathbf{4})$ & $26 / \mathbf{2 2}(9 / \mathbf{3})$ & $24 / \mathbf{1 2}(13 / \mathbf{6})$ \\
$2005-2006$ & $309 / \mathbf{3 1 4}(9 / \mathbf{4})$ & $320 / \mathbf{3 3 2}(15 / \mathbf{4})$ & $326 / \mathbf{3 3 0}(8 / \mathbf{4})$ & $337 / \mathbf{3 4 4}(12 / \mathbf{4})$ & $28 / \mathbf{2 6}(11 / 7)$ & $30 / \mathbf{2 7}(18 / \mathbf{2 0})$ \\
$2006-2007$ & $312 / \mathbf{3 1 7}(9 / \mathbf{3})$ & $310 / \mathbf{3 1 6}(9 / \mathbf{5})$ & $331 / 335(7 / \mathbf{3})$ & $328 / \mathbf{3 3 2}(8 / \mathbf{3})$ & $26 / \mathbf{2 4}(5 / \mathbf{2})$ & $24 / \mathbf{1 9}(9 / 7)$ \\
$2007-2008$ & $311 / \mathbf{3 1 6}(8 / \mathbf{3})$ & $318 / \mathbf{3 2 6}(10 / \mathbf{4})$ & $329 / 333(8 / \mathbf{4})$ & $338 / \mathbf{3 4 3}(9 / \mathbf{4})$ & $27 / \mathbf{2 6}(4 / \mathbf{2})$ & $24 / \mathbf{1 6}(10 / \mathbf{6})$ \\
2008-2009 & $320 / \mathbf{3 3 0}(13 / \mathbf{6})$ & $330 / \mathbf{3 4 2}(15 / \mathbf{6})$ & $334 / \mathbf{3 4 0}(8 / \mathbf{4})$ & $344 / \mathbf{3 5 2}(12 / \mathbf{3})$ & $12 / \mathbf{1 0}(4 / \mathbf{3})$ & $15 / \mathbf{9}(8 / \mathbf{5})$ \\
Average & $311 / \mathbf{3 1 8}(11 / \mathbf{4})$ & $318 / \mathbf{3 2 8}(11 / \mathbf{3})$ & $329 / \mathbf{3 3 3}(6 / \mathbf{4})$ & $336 / \mathbf{3 4 3}(9 / \mathbf{4})$ & $26 / \mathbf{2 3}(9 / \mathbf{3})$ & $25 / \mathbf{1 7}(11 / 7)$ \\
\hline
\end{tabular}

\section{Results and discussion}

\subsection{Spatio-temporal variability of lake ice phenology variables}

The algorithm described above was applied to all interpolated $10 \mathrm{~km}$ pixels on GBL and GSL for every day during the period 2002-2009 to produce maps of FO, ice-on, MO and ice-off dates, as well as freeze duration (FD), melt duration (MD), and ice cover duration (ICD) averaged over all years (Figs. 4-5). Recognizing that the relatively coarse spatial resolution of the product leads to a certain level of land contamination in $T_{\mathrm{B}}$ values along lakeshores and where a high concentration of islands exists (e.g. eastern arm of GSL), confidence regions were drawn on the two lakes with an outer buffer zone of $10 \mathrm{~km}$. Average dates and duration of the ice phenology variables calculated from all pixels over the greatest extent as possible for the lakes as well as within the confidence regions are included in Tables 3-5. Interestingly, in Tables 3-5 one can see that the standard deviations of ice phenology variables are almost always larger for GSL than for GBL, indicating that ice phenology processes are generally more variable spatially (i.e. between pixels) on the former lake which is located at a more southern latitude.

\subsubsection{Freeze-up period}

Once water cools to the freezing point, ice begins to form first in shallow near shore areas. Freeze-up is influenced primarily by air temperature and to a lesser extent by wind, in addition to lake depth. On average, the date of FO occurs approximately one week earlier on GBL than on its southern counterpart, GSL (Table 3). For GBL, the latest FO date over the study period occurred during ice season 2008-2009 (Day of Year or DY 330, late November) followed by 2003-2004 (DY 322). The earliest FO date happened in 2004-2005 (DY 308, early November). For GSL, both the 2005-2006 and 2008-2009 ice seasons experienced the latest FO dates of DY 332 and 342, respectively. The earliest FO date occurred in 2006-2007 on DY 316, closely followed by $2004-2005$ (DY 322). In addition to the effect of fall temperature in explaining earlier/later FO dates, an early ice break-up (longer period of solar radiation absorption by water) and warmer summer of the preceding months can result in the late onset of freeze-up for the two large, deep, lakes that store a considerable amount of heat during the open water season (Brown and Duguay, 2010). The latter process may be the case for ice season 2008-2009. Noteworthy is the fact that, in contrast to GBL, GSL's timing of ice formation is somewhat influenced by river inflow from the Slave River in its southeast section (Howell et al., 2009). A slight delay in FO is noticeable during most years at its mouth (see Figs. 1 and 4). GBL's ice regime is not affected by such inflow (Fig. 4).

Similar to FO, ice-on occurs approximately one week later on GSL than on GBL. The average ice-on date occurs on DY 333 and 343 for GBL and GSL, respectively (Table 3). Schertzer et al. (2008) and Walker et al. (2000) estimated average CFO in the main basin of the GSL to occur on DY 342 for the period 1988-2003. Spatially, for GBL (Fig. 4 and Table 3), the ice-on dates take place in the Central Basin around early December and for GSL, the ice-on dates occur in mid-December. From FO to ice-on, it takes two to three weeks on both lakes. For GBL, the longest FD over the study period happened during ice season 2003-2004 (28 days), closely followed by 2005-2006 and 2007-2008 (26 days). The shortest FD occurred in 2008-2009 (10 days) (Table 3). For GSL, the longest FD took place during ice season 2005-2006 (27 days), while the shortest FD happened in 2008-2009 (9 days) (Table 3). FD in GBL usually takes about 1-2 weeks longer than that in GSL, likely due to the fact that water depths in the confidence region of GBL range from 50 and $200 \mathrm{~m}$, while they vary between $20 \mathrm{~m}$ and $80 \mathrm{~m}$ in GSL; GBL therefore takes longer to lose its heat. Furthermore, FD mainly depends on air temperature variability after fall overturning which occurs at $+4{ }^{\circ} \mathrm{C}$.

Freezing Degree Days (FDD), calculated as the sum of mean daily air temperatures below $0{ }^{\circ} \mathrm{C}$ measured at a 

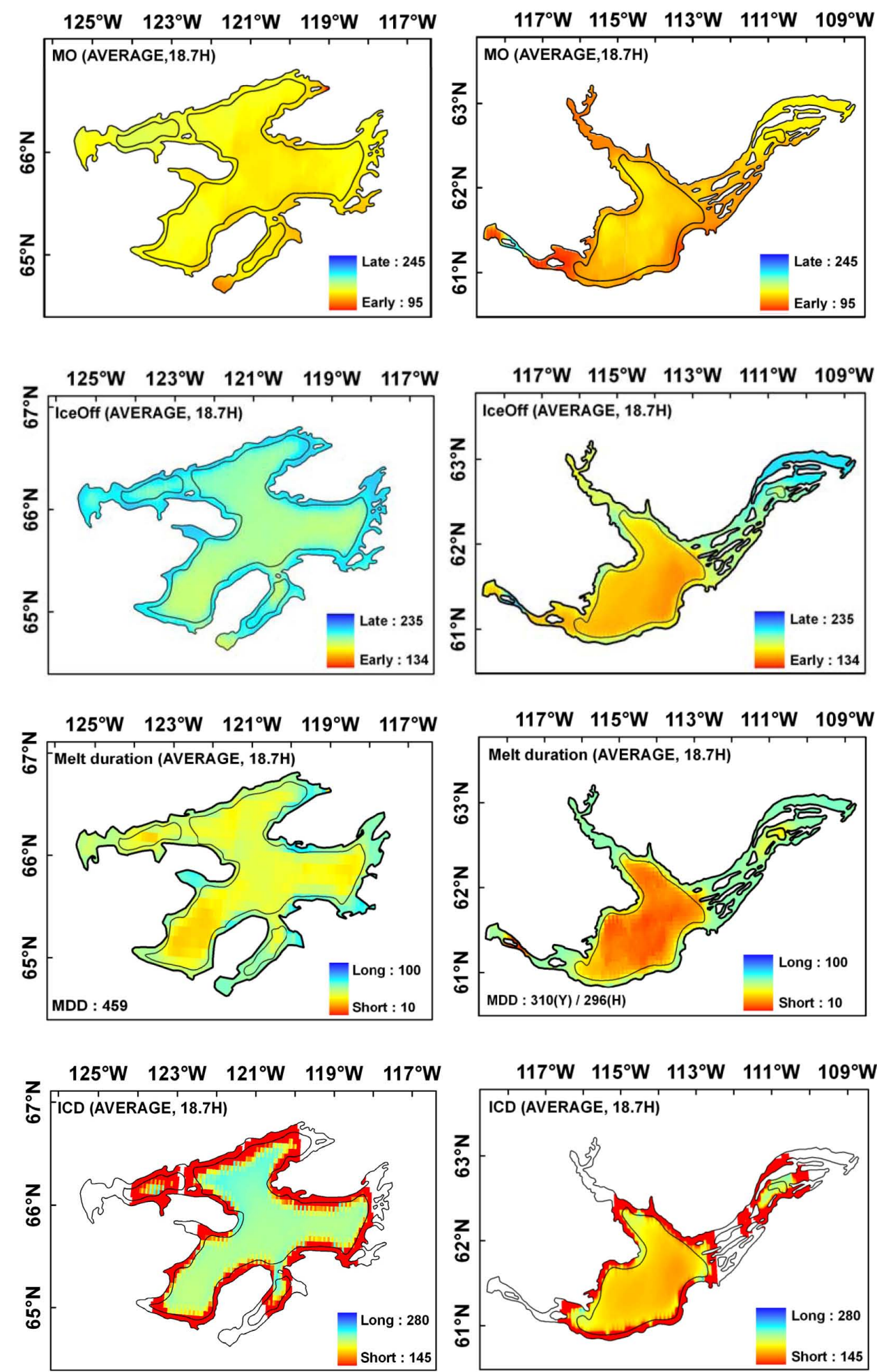

Fig. 5. Melt-onset (MO), ice-off, melt-duration, and ice-cover-duration (ICD) on average (2002-2009) for GBL (left panel) and GSL (right panel). Legend is day of year. 
Table 4. Summary of ice phenology variables during the break-up period (average day of melt-onset (MO) and ice-off, and number of days of melt duration (MD)) for GBL and GSL (2002-2009). Values within confidence regions in bold. Standard deviation in parentheses.

\begin{tabular}{lllllll}
\hline \multirow{2}{*}{ Year } & \multicolumn{2}{c}{ MO } & \multicolumn{2}{c}{ Ice-Off } & \multicolumn{2}{c}{ MD } \\
\cline { 2 - 7 } & GBL & GSL & GBL & GSL & GBL & GSL \\
\hline $2002-2003$ & $133 / \mathbf{1 2 7}(14 / \mathbf{1 2})$ & $132 / \mathbf{1 3 7}(14 / \mathbf{5})$ & $193 / \mathbf{1 8 3}(14 / 7)$ & $172 / \mathbf{1 5 7}(19 / \mathbf{2})$ & $61 / \mathbf{5 5}(15 / \mathbf{1 2})$ & $41 / \mathbf{1 9}(21 / \mathbf{4})$ \\
$2003-2004$ & $156 / \mathbf{1 5 5}(3 / \mathbf{2})$ & $147 / \mathbf{1 5 0}(16 / \mathbf{6})$ & $203 / \mathbf{1 9 8}(7 / \mathbf{4})$ & $186 / \mathbf{1 6 9}(20 / \mathbf{4})$ & $47 / \mathbf{4 3}(7 / \mathbf{4})$ & $39 / \mathbf{1 9}(19 / \mathbf{7})$ \\
$2004-2005$ & $133 / \mathbf{1 3 2}(11 / 7)$ & $124 / \mathbf{1 3 1}(21 / \mathbf{1 7})$ & $193 / \mathbf{1 8 6}(11 / \mathbf{4})$ & $168 / \mathbf{1 5 5}(19 / \mathbf{4})$ & $60 / \mathbf{5 4}(13 / \mathbf{9})$ & $44 / \mathbf{2 4}(20 / \mathbf{1 7})$ \\
$2005-2006$ & $129 / \mathbf{1 2 8}(7 / \mathbf{4})$ & $119 / \mathbf{1 2 2}(9 / \mathbf{5})$ & $182 / \mathbf{1 6 9}(16 / \mathbf{5})$ & $161 / \mathbf{1 4 0}(21 / \mathbf{6})$ & $53 / \mathbf{4 1}(16 / 7)$ & $42 / \mathbf{1 7}(22 / 7)$ \\
$2006-2007$ & $142 / \mathbf{1 4 1}(10 / \mathbf{6})$ & $124 / \mathbf{1 2 9}(17 / \mathbf{6})$ & $197 / \mathbf{1 8 7}(12 / \mathbf{6})$ & $166 / \mathbf{1 5 3}(19 / \mathbf{5})$ & $55 / \mathbf{4 6}(13 / \mathbf{1 0})$ & $42 / \mathbf{2 4}(18 / \mathbf{6})$ \\
$2007-2008$ & $149 / \mathbf{1 5 2}(9 / \mathbf{9})$ & $133 / \mathbf{1 3 5}(16 / \mathbf{1 0})$ & $187 / \mathbf{1 8 3}(10 / \mathbf{4})$ & $170 / \mathbf{1 5 6}(20 / \mathbf{2})$ & $38 / \mathbf{3 1}(13 / \mathbf{8})$ & $37 / \mathbf{2 0}(20 / \mathbf{9})$ \\
$2008-2009$ & $167 / \mathbf{1 6 8}(8 / 7)$ & $135 / \mathbf{1 3 7}(18 / \mathbf{1 4})$ & $200 / \mathbf{1 9 7}(6 / \mathbf{3})$ & $177 / \mathbf{1 6 7}(16 / \mathbf{3})$ & $33 / \mathbf{2 8}(10 / \mathbf{8})$ & $42 / \mathbf{3 0}(16 / \mathbf{1 2})$ \\
Average & $144 / \mathbf{1 4 3}(6 / \mathbf{3})$ & $131 / \mathbf{1 3 4}(12 / \mathbf{5})$ & $194 / \mathbf{1 8 6}(9 / \mathbf{3})$ & $171 / \mathbf{1 5 7}(17 / \mathbf{3})$ & $50 / \mathbf{4 3}(10 / \mathbf{5})$ & $41 / \mathbf{2 2}(17 / \mathbf{4})$ \\
\hline
\end{tabular}

Table 5. Summary of ice cover duration (ICDp) and open water season (OWS) (average number of days) for GBL and GSL (2002-2009). Values within confidence regions in bold. Standard deviation in parentheses. Note that OWS was not calculated for 2009 since it requires ice-on date to be known for fall freeze-up period 2009, which was not determined in this study.

\begin{tabular}{lllllll}
\hline \multirow{2}{*}{ Year } & \multicolumn{2}{c}{ ICD } & \multirow{2}{*}{ Year } & \multicolumn{2}{c}{ OWS } \\
\cline { 2 - 3 } \cline { 5 - 6 } & GBL & GSL & & GBL & GSL \\
\hline $2002-2003$ & $224 / \mathbf{2 1 5}(19 / \mathbf{1 1})$ & $195 / \mathbf{2 2 0}(28 / \mathbf{2 9})$ & 2003 & & $123 / \mathbf{1 1 6}(23 / \mathbf{2 2})$ & $151 / \mathbf{1 7 2}(28 / \mathbf{5})$ \\
$2003-2004$ & $233 / \mathbf{2 2 6}(12 / 7)$ & $203 / \mathbf{2 2 3}(22 / \mathbf{2 2})$ & 2004 & & $102 / \mathbf{9 7}(13 / \mathbf{1 3})$ & $130 / \mathbf{1 5 4}(28 / \mathbf{6})$ \\
$2004-2005$ & $232 / \mathbf{2 2 9}(10 / 7)$ & $195 / \mathbf{2 1 8}(20 / \mathbf{2 2})$ & 2005 & & $119 / \mathbf{1 1 2}(16 / \mathbf{1 6})$ & $155 / \mathbf{1 7 6}(27 / \mathbf{6})$ \\
$2005-2006$ & $210 / \mathbf{2 0 3}(15 / 7)$ & $176 / \mathbf{2 0 1}(26 / \mathbf{2 6})$ & 2006 & & $136 / \mathbf{1 3 2}(21 / \mathbf{2 1})$ & $156 / \mathbf{1 7 7}(26 / 7)$ \\
$2006-2007$ & $225 / \mathbf{2 1 7}(14 / \mathbf{8})$ & $195 / \mathbf{2 1 4}(17 / \mathbf{2 1})$ & 2007 & & $117 / \mathbf{1 1 3}(17 / \mathbf{1 6})$ & $155 / \mathbf{1 7 2}(24 / 7)$ \\
$2007-2008$ & $219 / \mathbf{2 1 5}(10 / \mathbf{6})$ & $184 / \mathbf{1 9 3}(12 / \mathbf{1 4})$ & 2008 & & $134 / \mathbf{1 2 5}(20 / \mathbf{2 0})$ & $162 / \mathbf{1 8 6}(30 / \mathbf{6})$ \\
$2008-2009$ & $230 / \mathbf{2 2 3}(11 / \mathbf{5})$ & $193 / \mathbf{2 0 8}(18 / \mathbf{1 9})$ & & & & \\
Average & $225 / \mathbf{2 1 8}(9 / \mathbf{6})$ & $192 / \mathbf{2 1 1}(16 / \mathbf{1 8})$ & Average & $122 / \mathbf{1 1 6}(15 / \mathbf{1 4})$ & $152 / \mathbf{1 7 3}(32 / \mathbf{5})$ \\
\hline
\end{tabular}

meteorological station, and given in the bottom left of Fig. 4 provide some indication of the effect of colder/warmer temperatures on FD. FDD calculated here between FO and iceon date in each ice season. One should bear in mind, however, that heat storage during the preceding open water season will also have an impact on FD. Due to this, the relation between FDD and FD is not always consistent from year to year for the two lakes.

\subsubsection{Break-up period}

The break-up process is primarily influenced by air temperature variability, causing earlier or later MO dates on the two lakes. The MO dates mark the beginning of melt of snow on the ice surface or the initiation of melt of ice in the case when a bare ice surface is encountered. Differences in the timing of MO between GBL and GSL can largely be explained due to spring air temperature differences (Table 2). MO dates occur approximately one week earlier on GSL than on GBL (Table 4). The average MO date occurs on DY 143 (end May) on GBL and DY 135 (mid May) on GBL (see Fig. 5). For GBL, the earliest MO dates happened on DY 127 (2002-2003) and the latest MO dates occurred in 2003-2004 (DY 155, early June) (Table 4). For GSL, the earliest MO date occurred on DY 122 (early May) in 2005-2006 and the latest date took place in 2003-2004 (DY 150, early June). Earlier (later) MO dates appears to be related to warm (cool) spring air temperature (Table 2). The warmer average spring air temperature $\left(-7.8^{\circ} \mathrm{C}\right.$ and $-1.0^{\circ} \mathrm{C}$ for GBL and GSL, respectively) caused earlier MO dates to occur in ice season 2005-2006, while the colder spring of ice season $2003-2004\left(-11.7^{\circ} \mathrm{C}\right.$ and $-7.6^{\circ} \mathrm{C}$ for GBL and GSL, respectively) resulted in later MO dates.

In contrast to MO, the average ice-off dates on GSL are about four weeks earlier (DY 157 - early June) than on GBL (DY 183 - early July) (see Fig. 5). For GBL, the latest ice-off date occurred during ice season 2003-2004 on DY 198 (mid July). The earliest ice-off date occurred in 2005-2006 on DY 169 (mid June) (Table 4). For GSL, the 2003-2004 ice season experienced the latest ice-off dates of DY 169 (mid June). The earliest ice-off date for this lake happened in 2005-2006 on DY 140 (mid May) (Table 4). Early ice-off 
dates lengthen the open water season during the high solar period in spring/summer, resulting in a longer period of solar radiation absorption by the lakes and, subsequently, higher lake temperatures in late summer/early fall due to larger heat storage. Looking at specific ice cover seasons, the colder spring/early summer climate conditions of 2004 and 2009 contributed to later break-up, while the warmest conditions of 2006 influenced earlier break-up (Table 4). On GSL, iceoff dates are earlier in the majority of years at the mouth of the Slave River which brings warmer water as this river flows from the south into the lake (see Fig. 5). For GBL, however, ice-off dates are not influenced by similar river inflow such that melt generally proceeds gradually from the more southern (warmer) to the northern sections of the lake. Unlike MO, the larger difference in ice-off dates between the two lakes (about four weeks) can be explained by a combination of thicker ice and colder spring/early summer conditions at GBL which, as a result, requires a greater number of days above $0{ }^{\circ} \mathrm{C}$ to completely melt the ice.

The average melt duration (MD), which encompasses the period from MO to ice-off, takes two to five weeks longer on GBL than on GSL (Table 4). For GBL, the longest MD was 55 days in 2002-2003 but was only 28 days in 2008-2009 (Table 4). For GSL, the longest MD lasted 30 days in 20082009, whereas the shortest MD took 17 days in 2005-2006 (Table 4). The length of the MD is mainly controlled by the combination of end-of-winter maximum ice thicknesses and spring/early summer temperatures. In general, the thinner the ice is before melt begins and the warmer the temperature conditions are between MO and ice-off, the shorter the MD lasts. One exception is the central basin of GSL, where MD is also influenced by the inflow of water from Slave River which helps to accelerate the break-up process in this lake. Melting Degree Days (MDD), calculated as the sum of mean daily air temperatures above $0{ }^{\circ} \mathrm{C}$ at a meteorological station from MO until ice-off, provide some indication of the effect of colder/warmer temperatures in spring/early summer on MD for each ice season (see bottom left corner of Fig. 5). Visually, a relation appears to exist between long/short MD and low/high MDD for GBL. Such a relation does not seem to be present for GSL, likely as a result of the inflow of water from Slave River.

\subsubsection{Ice cover duration}

The average ice cover duration (ICD), which is calculated as the number of days between ice-on and ice-off dates, is one week shorter for GSL than for GBL over the full period of analysis (DY 218 and 211 on average, respectively). However, the length of the ICD can differ by as much as four to five weeks between the two lakes in some years. For GBL, the longest ICD was 229 days in 2004-2005, while the shortest lasted 203 days (2005-2006). For GSL, the longest ICD lasted 223 days (2003-2004), while the shortest was 193 days (2007-2008) (Table 5). In GBL's Smith Arm and Dease
Arm (northern section of lake), lake ice stays longer than in the other arms, up until the middle (or end) of July (Fig. 5), particularly during the two cold winter seasons of 2003-2004 and 2008-2009. For GSL, shorter ICD occurs at the mouth of Slave River and near Yellowknife compared to the east arm of the lake (Fig. 5). ICD is influenced by river inflow from Slave River for the full period of study (2002-2009), as it has a particularly large influence on ice-off dates (see Fig. 5).

\subsection{Comparison of AMSR-E ice phenology variables with other satellite-derived ice products}

While the AMSR-E retrieval algorithm captures well the spatial patterns and seasonal evolution of ice cover on GBL and GSL over several ice seasons, estimated dates of the various ice phenology variables should be compared to those determined from other approaches and with different satellite sensors whenever possible, as to provide at least a qualitative assessment of the level of agreement with existing products. A detailed quantification of uncertainty (biases) of the various ice products is, however, beyond the scope of this paper. This is a topic that merits investigation in a follow-up study encompassing a larger number of lakes.

\subsubsection{Comparison with other pixel-based products}

Tables 6-8 present summary statistics of ice phenology variables estimated at the pixel level from AMSR-E $T_{\mathrm{B}}$ (20022009) against those obtained with daily QuikSCAT (20022006; Howell et al., 2009) and NOAA/IMS products (20042009). Values in these tables are the averages and standard deviations calculated from all pixels over the complete lakes and their main basin (confidence regions). IMS ice variables consist of ice-on/ice-off dates and ICDp, while QuikSCATderived variables are comprised of $\mathrm{FO} / \mathrm{MO} / \mathrm{ice}$-off dates and ICDp calculated from FO to ice-off dates. The complex nature of the freeze-up process has been reported to make the distinction between FO and ice-on dates difficult from analysis of the temporal evolution of backscatter $\left(\sigma^{\circ}\right)$ from QuikSCAT (Howell et al., 2009). This can be explained by the fact that QuikSCAT-derived ice phenology variables are influenced by deformation features such as ice rafts, windroughened water in cracks, and ridge formation during the freeze-up period, acting to increase $\sigma^{\circ}$. However, time series of AMSR-E $T_{\mathrm{B}}$ at $18.7 \mathrm{GHz}(\mathrm{H}-\mathrm{pol})$ can differentiate $\mathrm{FO}$ from ice-on dates (see Fig. 2) as $T_{\mathrm{B}}$ is largely controlled by changes in emissivity progressively from the radiometrically cold open water to the warmer ice-covered lake surface, and not as much by lake ice surface roughness, during the freezeup period.

FO dates as determined from AMSR-E are about one week earlier on average (7-11 days for GBL; 1-8 days for GSL) than those derived with QuikSCAT when considering the two 

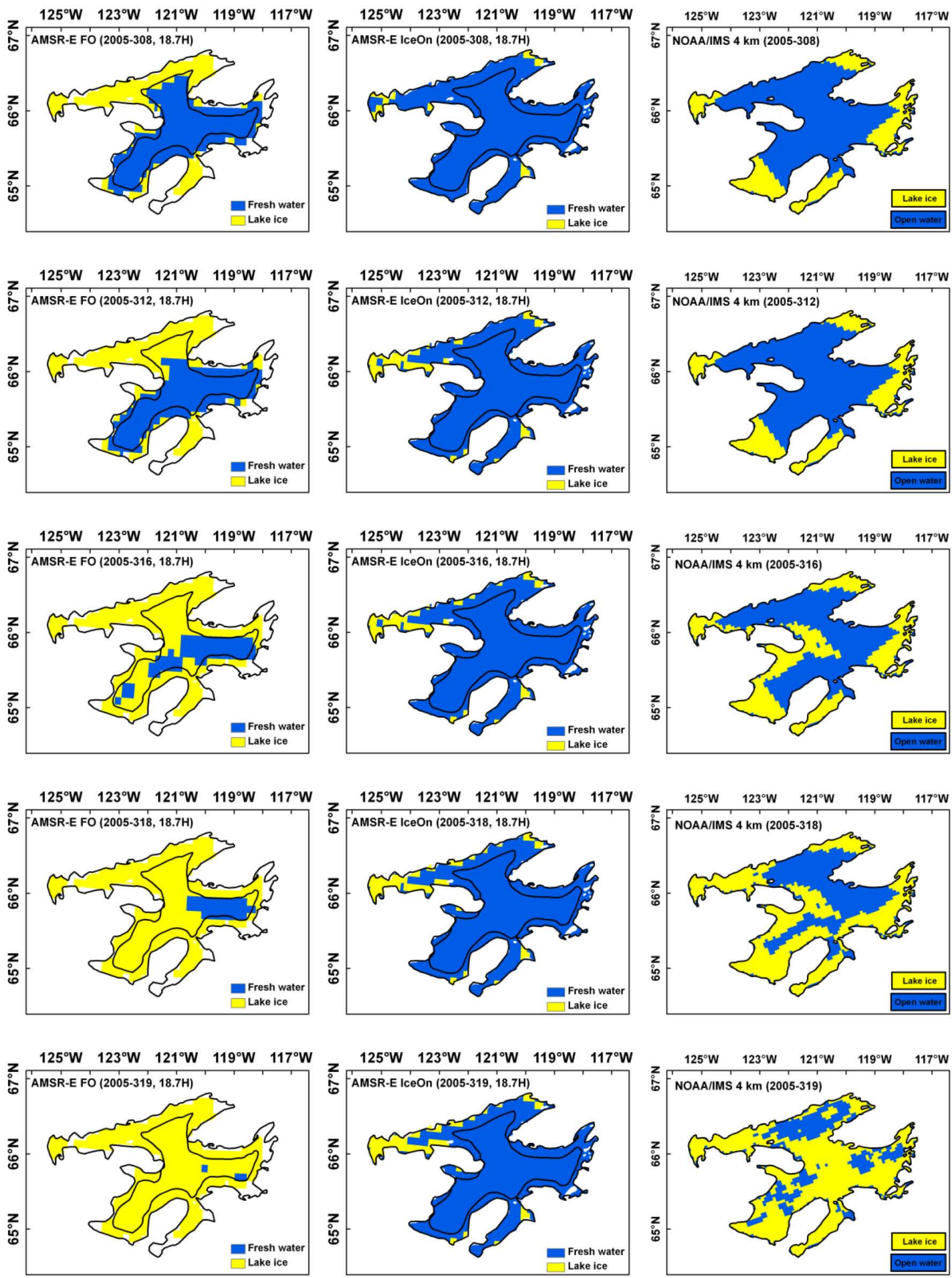

Fig. 6. Comparison of AMSR-E freeze-onset (left), ice-on (center), and NOAA/IMS ice-on (right) (day of year) during the freeze-up period of ice season 2005-2006 on GBL. 

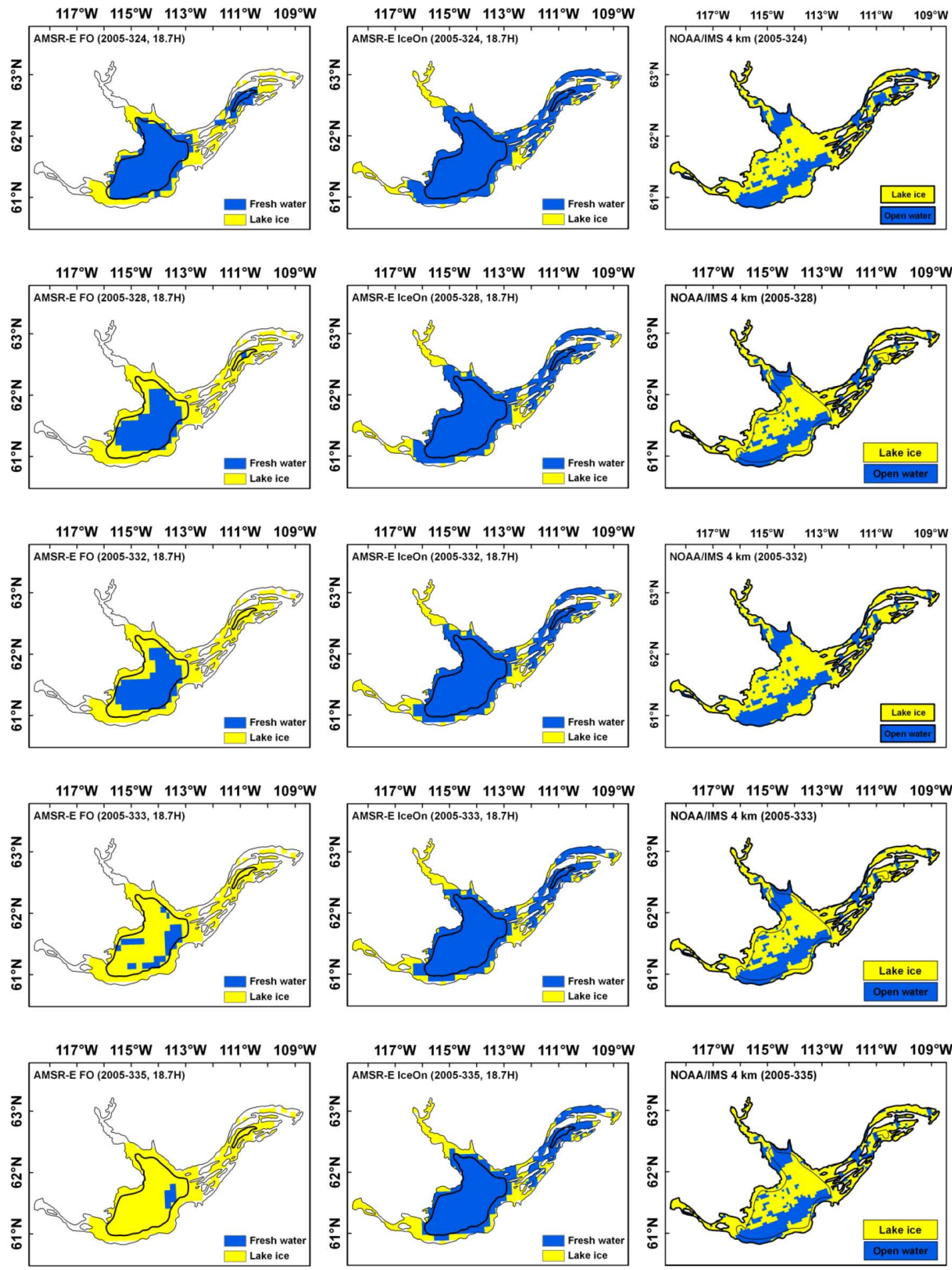

Fig. 7. Comparison of AMSR-E freeze-onset (left), ice-on (center), and NOAA/IMS ice-on (right) (day of year) during the freeze-up period of ice season 2005-2006 on GSL. 

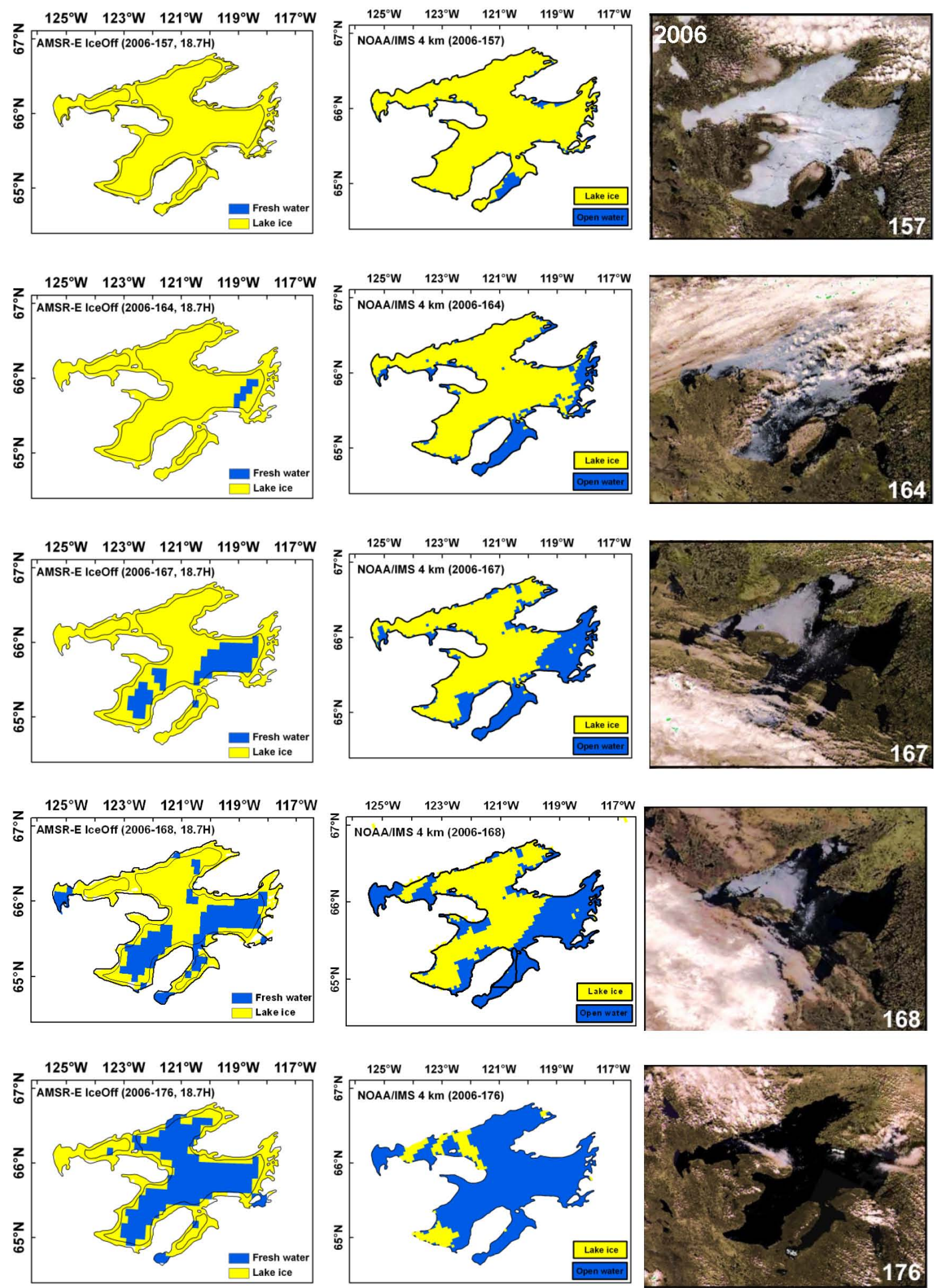

Fig. 8. Comparison of AMSR-E (left) and NOAA/IMS (center) ice-off, and MODIS/Terra image (right) acquired on the same day during the break-up period of ice season 2005-2006 on GBL. 

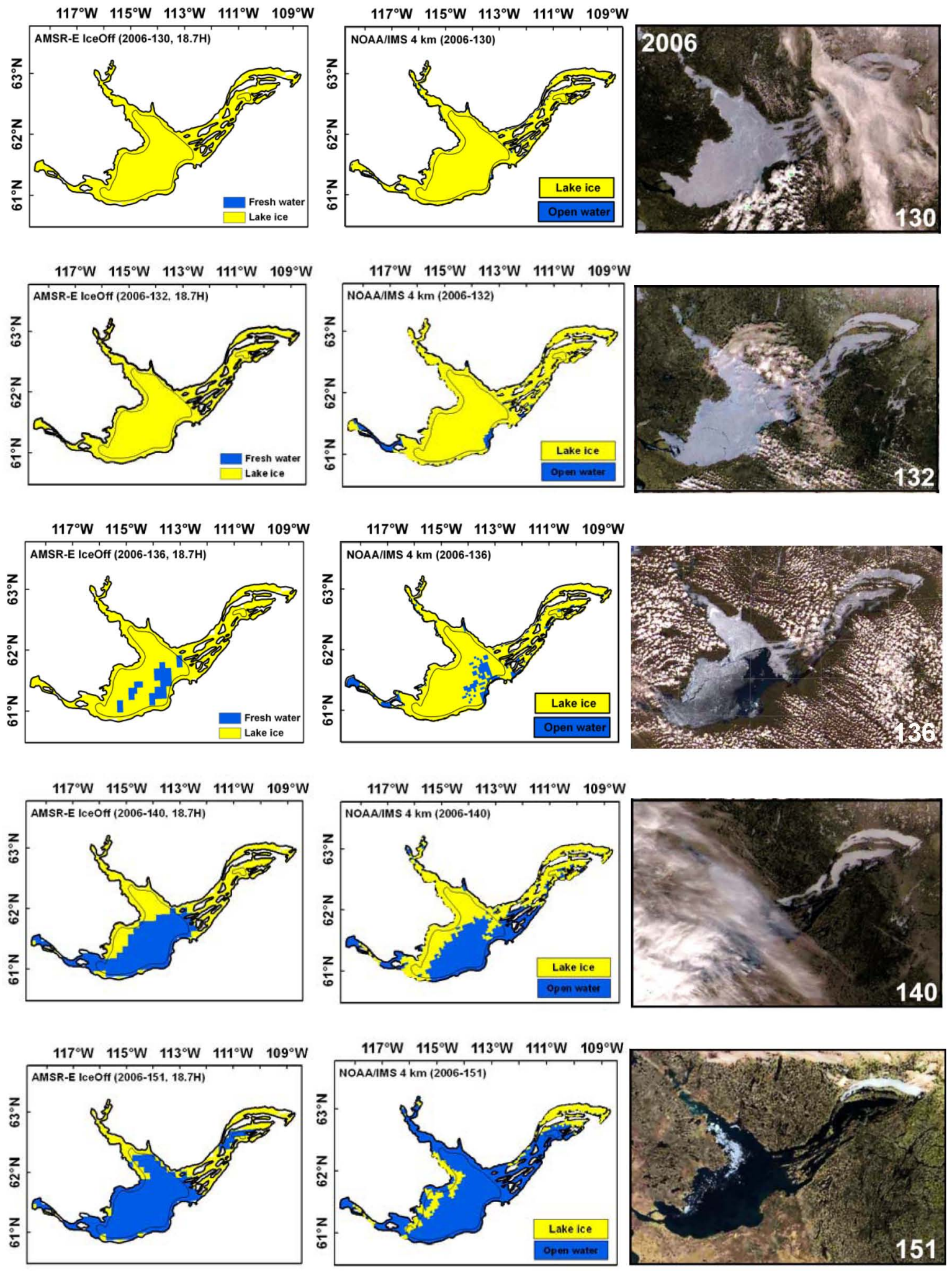

Fig. 9. Comparison of AMSR-E (left) and NOAA/IMS (center) ice-off, and MODIS/Terra image (right) acquired on the same day during the break-up period of ice season 2005-2006 on GSL. 
Table 6. Comparison of ice phenology variables for freeze-up period (FO and Ice-On) daily-derived from AMSR-E (AME), QuikSCAT (QUT) and NOAA/IMS (IMS) products for GBL and GSL (2002-2009). Values within confidence regions in bold. Standard deviation in parentheses.

\begin{tabular}{|c|c|c|c|c|c|c|c|c|}
\hline \multirow{2}{*}{ Pixel Level } & \multicolumn{4}{|l|}{ FO } & \multicolumn{3}{|c|}{ Ice-On } & \\
\hline & GBL & & GSL & & GBL & & GSL & \\
\hline YEAR & AME & QUT & AME & QUT & AME & IMS & AME & IMS \\
\hline 0203 & $311 / 320(14 / 7)$ & $330(8)$ & $318 / 331(18 / 4)$ & $335(8)$ & $328 / 333(11 / 7)$ & & $334 / 345(17 / 7)$ & \\
\hline 0304 & $313 / 322(11 / \mathbf{5})$ & $309(9)$ & $319 / 329(14 / 5)$ & $332(8)$ & $332 / 337(8 / \mathbf{5})$ & & $338 / 345(11 / 5)$ & \\
\hline 0405 & $303 / 308(9 / 4)$ & $314(6)$ & $313 / 322(13 / 3)$ & $325(8)$ & $321 / 323(6 / 4)$ & $316 / 322(9 / 8)$ & $331 / 338(12 / 4)$ & $315 / \mathbf{3 1 9}(9 / \mathbf{8})$ \\
\hline 0506 & $309 / 314(9 / 4)$ & $321(9)$ & $320 / 332(15 / 4)$ & $333(6)$ & $326 / 330(8 / 4)$ & $319 / 322(11 / \mathbf{1 0})$ & $337 / 344(12 / 4)$ & $327 / 330(10 / \mathbf{1 0})$ \\
\hline 0607 & $312 / 317(9 / 3)$ & $325(6)$ & $310 / \mathbf{3 1 6}(9 / \mathbf{5})$ & $324(5)$ & $331 / 335(7 / 3)$ & $327 / 332(14 / 7)$ & $328 / 332(8 / 3)$ & 327/331 (10/9) \\
\hline 0708 & $311 / 316(8 / 3)$ & & $318 / 326(10 / 4)$ & & $329 / 333(8 / 4)$ & $325 / 329(13 / 9)$ & $338 / 343(9 / 4)$ & $328 / \mathbf{3 3 8}(16 / \mathbf{1 5})$ \\
\hline 0809 & $320 / 330(13 / 6)$ & & $330 / 342(15 / 6)$ & & $334 / 340(8 / 4)$ & $323 / \mathbf{3 2 9}(12 / \mathbf{1 2})$ & $344 / 352(12 / 3)$ & $328 / 338(14 / 11)$ \\
\hline AVG & $311 / 318(11 / 4)$ & & $318 / 328(11 / 3)$ & & $329 / 333(6 / 4)$ & $322 / 327(12 / 9)$ & $336 / 343(9 / 4)$ & $325 / \mathbf{3 3 1}(12 / \mathbf{1 1})$ \\
\hline
\end{tabular}

Table 7. Comparison of ice phenology variables for break-up period (MO and Ice-Off) daily-derived from AMSR-E (AME), QuikSCAT (QUT) and NOAA/IMS (IMS) products for GBL and GSL (2002-2009). Values within confidence regions in bold. Standard deviation in parentheses.

\begin{tabular}{|c|c|c|c|c|c|c|c|c|c|c|}
\hline \multirow{2}{*}{ Pixel Level } & \multicolumn{4}{|l|}{ MO } & \multicolumn{6}{|l|}{ Ice-Off } \\
\hline & GBL & & GSL & & GBL & & & GSL & & \\
\hline YEAR & AME & QUT & AME & QUT & AME & QUT & IMS & AME & QUT & IMS \\
\hline 0203 & 133/127 (14/12) & $117(8)$ & 132/137 (14/5) & $112(5)$ & $193 / \mathbf{1 8 3}(14 / 7)$ & $189(6)$ & & 172/157 (19/2) & $163(6)$ & \\
\hline 0304 & $156 / \mathbf{1 5 5}(3 / \mathbf{2})$ & $149(2)$ & $147 / 150(16 / 6)$ & $143(8)$ & $203 / 198$ (7/4) & $205(3)$ & 202/204 (8/6) & $186 / 169(20 / 4)$ & $178(5)$ & 176/174 (17/14) \\
\hline 0405 & 133/132 (11/7) & $152(14)$ & $124 / \mathbf{1 3 1}(21 / \mathbf{1 7})$ & $100(1)$ & $193 / \mathbf{1 8 6}(11 / \mathbf{4})$ & $193(5)$ & $188 / \mathbf{1 8 8}(12 / 7)$ & $168 / \mathbf{1 5 5}(19 / 4)$ & $164(7)$ & $166 / 160(12 / 10)$ \\
\hline 0506 & $129 / 128(7 / 4)$ & $127(10)$ & $119 / \mathbf{1 2 2}(9 / \mathbf{5})$ & $118(16)$ & $182 / \mathbf{1 6 9}(16 / 5)$ & $174(5)$ & $171 / \mathbf{1 7 2}(12 / \mathbf{1 0})$ & $161 / \mathbf{1 4 0}(21 / \mathbf{6})$ & 151 (11) & 148/145 (13/10) \\
\hline 0607 & $142 / \mathbf{1 4 1}(10 / \mathbf{6})$ & & $124 / \mathbf{1 2 9}(17 / \mathbf{6})$ & & $197 / \mathbf{1 8 7}(12 / \mathbf{6})$ & & $187 / \mathbf{1 8 7}(13 / \mathbf{9})$ & $166 / \mathbf{1 5 3}(19 / \mathbf{5})$ & & $159 / \mathbf{1 5 8}(14 / \mathbf{6})$ \\
\hline 0708 & $149 / \mathbf{1 5 2}(9 / \mathbf{9})$ & & $133 / \mathbf{1 3 5}(16 / \mathbf{1 0})$ & & $187 / 183(10 / 4)$ & & $185 / \mathbf{1 8 8}(9 / 7)$ & $170 / \mathbf{1 5 6}(20 / \mathbf{2})$ & & $161 / 159(13 / 5)$ \\
\hline 0809 & $167 / 168(8 / 7)$ & & $135 / \mathbf{1 3 7}(18 / \mathbf{1 4})$ & & $200 / \mathbf{1 9 7}(6 / \mathbf{3})$ & & $198 / \mathbf{2 0 0}(12 / \mathbf{5})$ & $177 / 167(16 / 3)$ & & $175 / 174(19 / 7)$ \\
\hline AVG & $144 / \mathbf{1 4 3}(6 / 3)$ & & $131 / \mathbf{1 3 4}(12 / \mathbf{5})$ & & $194 / \mathbf{1 8 6}(9 / 3)$ & & $189 / 190(11 / 7)$ & $171 / 157(17 / 3)$ & & $164 / 162(15 / 9)$ \\
\hline
\end{tabular}

lakes over the five years available for comparison (Table 6). AMSR-E $T_{\mathrm{B}}$ may be more sensitive to within-pixel fractional presence of ice and less to wind-induced surface roughness over open water areas than $\sigma^{\circ}$ from QuikSCAT. Regarding ice-on dates, AMSR-E (from DY 323 to 352) and IMS (from DY 319 to 338) show a difference of about one week on average, with AMSR-E detecting ice-on later. In fact, and as illustrated in Figs. 6-7, NOAA/IMS ice-on patterns follow AMSR-E FO more closely than ice-on. Interestingly, IMS ice-on remains the same between DY 324 and DY 335 on GSL (Fig. 7) while FO evolves over the same period in AMSR-E. This indicates that extensive cloud cover during this period may have been a limiting factor in determining the presence of ice and open water on GSL by ice analysts who largely rely on the use of optical satellite data in preparing the IMS product.

The difference in MO dates is very variable between AMSR-E and QuikSCAT, ranging anywhere between a single day to four weeks (Table 7). During the break-up period, $\sigma^{\circ}$ seems more sensitive to initial surface melt than $T_{\mathrm{B}}$ with QuikSCAT providing in all but one case earlier MO.
AMSR-E (from DY 140 to 198) and QuikSCAT ice-off dates (from DY 151 to 205) show similar inter-annual variability with a difference of about one week (Table 7). Average iceoff dates are also quite similar between AMSR-E and IMS with a difference of approximately five days. They also follow the same variability (later and earlier dates) between years. Although the number of years in this comparison between products is somewhat limited, these initial results suggest that ice-on is the most consistent ice phenology variable across products examined. This point is further supported by the similar spatial patterns in ice-on/ice-off determined from AMSR-E, IMS, and MODIS imagery over the break-up period of ice season 2005-2006 (Figs. 8 and 9).

AMSR-E ICDp differs by one week on average from IMS (Table 8). Ice cover is estimated to remain longer with IMS when examining the full extent of GBL and GSL. This is expected since IMS is a finer resolution product $(4 \mathrm{~km})$ that can resolve ice in areas of the lakes where AMSR-E suffers from land contamination (along lake shore and areas with small islands as in the east arm of GSL). When considering only the main basin sections of GBL and GSL (confidence regions), 
Table 8. Comparison of daily-derived ICDp from AMSR-E (AME), QuikSCAT (QUT) and NOAA/IMS (IMS) products for GBL and GSL (2002-2009). Values within confidence regions in bold. Standard deviation in parentheses. Note that QUT* indicates that ICDp was calculated from FO to ice-off since ice-on was not determined in Howell et al. (2009).

\begin{tabular}{|c|c|c|c|c|c|c|}
\hline \multirow{2}{*}{ Pixel Level } & \multicolumn{5}{|c|}{ ICDp } & \multirow[b]{3}{*}{ IMS } \\
\hline & GBL & & & GSL & & \\
\hline YEAR & AME & QUT* & IMS & AME & QUT* & \\
\hline 0203 & $224 / 215(19 / 11)$ & $224(13)$ & & $195 / 220(28 / 29)$ & $193(12)$ & \\
\hline 0304 & $233 / 226(12 / 7)$ & $260(11)$ & & $203 / 223(22 / 22)$ & $211(12)$ & \\
\hline 0405 & $232 / 229(10 / 7)$ & $245(9)$ & 238/232 (11/7.5) & $195 / 218(20 / 22)$ & $205(14)$ & 217/207 (11/9) \\
\hline 0506 & $210 / \mathbf{2 0 3}(15 / 7)$ & $218(13)$ & $217 / 216(12 / 10)$ & $176 / 201(26 / 26)$ & $183(16)$ & $186 / \mathbf{1 8 1}(12 / \mathbf{1 0})$ \\
\hline 0607 & 225/217 (14/8) & & 225/221 (14/8) & $195 / 214(17 / 21)$ & & 197/193 (12/7.5) \\
\hline 0708 & $219 / 215(10 / 6)$ & & $225 / \mathbf{2 2 5}(11 / \mathbf{8})$ & $184 / \mathbf{1 9 3}(12 / \mathbf{1 4})$ & & $198 / \mathbf{1 8 7}(15 / \mathbf{1 0})$ \\
\hline 0809 & $230 / \mathbf{2 2 3}(11 / \mathbf{5})$ & & $241 / \mathbf{2 3 7}(12 / \mathbf{8 . 5})$ & 193/208 (18/19) & & 213/202 (17/9) \\
\hline AVG & $225 / 218(9 / 6)$ & & $229 / \mathbf{2 2 6}(12 / \mathbf{8 . 3})$ & $192 / 211(16 / 18)$ & & 202/194 (13/9.6) \\
\hline
\end{tabular}

AMSR-E ICDp estimates are slightly shorter for GBL and longer for GSL than IMS (Table 8). Since ICDp is calculated from ice-on to ice-off dates such differences between the two products are possible. As indicated earlier, ice-on dates from IMS tend to fall between FO and ice-on dates from AMSR-E, but closer to FO. Differences in ICDp tend to be larger between AMSR-E and QuikSCAT estimates over two lakes, the main reason being that ICDp from QuikSCAT was calculated from FO, instead of ice-on to ice-off dates by Howell et al. (2009). This makes the comparison a bit more tentative than with the IMS product.

\subsubsection{Lake-wide comparison}

Table 9 shows summary statistics of CFO, WCI and ICDe estimated with AMSR-E compared to those determined from NOAA/IMS and by CIS. CFO corresponds to the date when all pixels within a lake or lake section become totally icecovered (i.e. $100 \%$ ice fraction), while $\mathrm{WCI}$ is the date when all pixels become ice-free (i.e. $100 \%$ open water). ICDe is calculated as the number of days between CFO and WCI. In Table 9, CFO/WCI/ICDe estimates from IMS and CIS are for the entire extent of GBL and GSL. Acknowledging that estimates of the same variables are derived at a coarser spatial resolution with AMSR-E, estimates are provided for both the entire lake surfaces and main basins only (confidence regions) of GBL and GSL. Also noteworthy is the fact that CIS is a weekly product, unlike the IMS and AMSR-E products that are derived daily. Therefore, some of the differences between estimated dates may be attributed to the temporal resolution of the products. AMSR-E/CFO (from DY 330 to 356) dates compare well with CIS/CFO (from DY 324 to 354 ) and IMS/CFO (from DY 326 to 348), as do AMSRE/WCI (from DY 158 to 210) with IMS/WCI (from DY 175 to 209) and CIS/WCI (from DY 165 to 219). Overall, these results are very encouraging since $\mathrm{CFO} / \mathrm{WCI} / \mathrm{ICDe}$ estimated with the new automated AMSR-E ice phenology retrieval algorithm are within about one week of those determined by ice analysts (IMS and CIS) through visual interpretation of imagery from various sources (optical and SAR). Some of the variability in estimates between years (earlier/later dates) should, however, be examined more closely in a follow-up study.

\section{Conclusions}

The $18.7 \mathrm{GHz}$ (H-pol) was found to be the most suitable AMSR-E channel for estimating ice phenology dates. It is less sensitive than the other frequencies examined to wind effects over open water and $\mathrm{H}$-pol is better than V-pol for discriminating open water from ice. As a result, an ice phenology retrieval algorithm which makes use of AMSRE $18.7 \mathrm{GHz} \mathrm{H}-$ pol $T_{\mathrm{B}}$ data was developed and applied to map the evolution of freeze-onset/melt-onset and ice-on/iceoff dates, as well as melt/freeze/ice cover duration on GBL and GSL over seven ice seasons (2002-2009). Through this, much was learned about the temporal and spatial evolution of ice cover within and between the two large lakes in relation to regional climate, latitudinal position, spring and summer temperature (for break-up), lake depth and, in the case of GSL, the influence of water inflow from Slave River. In addition, freeze duration is mainly dependent on air temperature variability after fall overturning. Results revealed that during the freeze-up period both freeze-onset and ice-on dates occur about one week earlier, and freeze duration lasts approximately one week longer on GBL than on GSL. During the break-up period, melt-onset and ice-off dates happen on average one week and approximately four weeks later, respectively, on GBL. Located in a colder climate region, melt duration lasts about three weeks longer on this lake compared to its southern counterpart. The net effect is that ice cover 
Table 9. Comparison of ice phenology variables (CFO, WCI, and ICDe) daily derived from AMSR-E (AME) and NOAA/IMS (IMS) products, as well as weekly-derived from Canada Ice Service (CIS) product for GBL and GSL (2002-2009). Values within confidence regions in bold. Standard deviation in parentheses.

\begin{tabular}{|c|c|c|c|c|c|c|c|c|c|c|c|c|c|c|c|c|c|c|}
\hline \multirow{3}{*}{$\begin{array}{l}\text { Entire } \\
\text { Lake } \\
\text { YEAR }\end{array}$} & \multicolumn{6}{|l|}{$\mathrm{CFO}$} & \multicolumn{6}{|l|}{ WCI } & \multicolumn{6}{|l|}{ ICDe } \\
\hline & GBL & & & GSL & & & GBL & & & GSL & & & GBL & & & GSL & & \\
\hline & AME & IMS & CIS & AME & IMS & CIS & AME & IMS & CIS & AME & IMS & CIS & AME & IMS & CIS & AME & IMS & CIS \\
\hline 0203 & $\begin{array}{l}346 \\
\mathbf{3 4 6}\end{array}$ & & 354 & $\begin{array}{l}351 \\
/ \mathbf{3 5 1}\end{array}$ & & 354 & $\begin{array}{l}210 / \\
210\end{array}$ & & 199 & $\begin{array}{l}210 \\
/ 160\end{array}$ & & 178 & $\begin{array}{l}229 / \\
229\end{array}$ & & 203 & $\begin{array}{l}224 \\
/ \mathbf{1 7 4}\end{array}$ & & 182 \\
\hline 0304 & $\begin{array}{l}344 \\
\text { /344 }\end{array}$ & & 339 & $\begin{array}{l}350 \\
/ 350\end{array}$ & & 346 & $\begin{array}{l}210 \\
/ 210\end{array}$ & 208 & 219 & $\begin{array}{l}210 \\
/ 194\end{array}$ & 202 & 198 & $\begin{array}{l}231 \\
/ 231\end{array}$ & & 238 & $\begin{array}{l}225 \\
/ 209\end{array}$ & & 210 \\
\hline 0405 & $\begin{array}{l}330 \\
/ \mathbf{3 3 0}\end{array}$ & 326 & 324 & $\begin{array}{l}344 \\
/ 344\end{array}$ & 326 & 338 & $\begin{array}{l}210 \\
/ 210\end{array}$ & 209 & 203 & $\begin{array}{l}210 \\
/ 166\end{array}$ & 186 & 196 & $\begin{array}{l}246 \\
/ 246\end{array}$ & 249 & 237 & $\begin{array}{l}232 \\
/ \mathbf{1 8 8}\end{array}$ & 226 & 216 \\
\hline 0506 & $\begin{array}{l}336 \\
1336\end{array}$ & 334 & 336 & $\begin{array}{l}349 \\
/ 349\end{array}$ & 340 & 343 & $\begin{array}{l}210 \\
/ 202\end{array}$ & 187 & 188 & $\begin{array}{l}207 \\
/ \mathbf{1 6 8}\end{array}$ & 183 & 165 & $\begin{array}{l}239 \\
/ \mathbf{2 3 1}\end{array}$ & 218 & 210 & $\begin{array}{l}223 \\
/ \mathbf{1 8 4}\end{array}$ & 208 & 182 \\
\hline 0607 & $\begin{array}{l}339 \\
\mathbf{3 3 9}\end{array}$ & 336 & 335 & $\begin{array}{l}337 \\
/ \mathbf{3 3 7}\end{array}$ & 337 & 335 & $\begin{array}{l}210 \\
/ 208\end{array}$ & 202 & 201 & $\begin{array}{l}210 \\
/ 164\end{array}$ & 175 & 187 & $\begin{array}{l}236 \\
/ 234\end{array}$ & 231 & 224 & $\begin{array}{l}238 \\
/ 192\end{array}$ & 203 & 210 \\
\hline 0708 & $\begin{array}{l}339 \\
\text { /339 }\end{array}$ & 345 & 341 & $\begin{array}{l}346 \\
/ 346\end{array}$ & 342 & 341 & $\begin{array}{l}210 \\
/ 193\end{array}$ & 195 & 200 & $\begin{array}{l}210 \\
/ \mathbf{1 5 8}\end{array}$ & 189 & 200 & $\begin{array}{l}236 \\
/ 219\end{array}$ & 215 & 217 & $\begin{array}{l}230 \\
/ \mathbf{1 7 8}\end{array}$ & 212 & 217 \\
\hline 0809 & $\begin{array}{l}348 \\
/ \mathbf{3 4 8}\end{array}$ & 331 & 333 & $\begin{array}{l}356 \\
/ 356\end{array}$ & 348 & 347 & $\begin{array}{l}210 \\
/ 204\end{array}$ & 208 & 212 & $\begin{array}{l}210 \\
/ \mathbf{1 7 2}\end{array}$ & 199 & 191 & $\begin{array}{l}228 \\
/ 222\end{array}$ & 243 & 237 & $\begin{array}{l}219 \\
/ \mathbf{1 8 1}\end{array}$ & 217 & 202 \\
\hline AVG & $\begin{array}{l}340 \\
/ 340 \\
(6 / 6)\end{array}$ & $\begin{array}{l}334 \\
(7)\end{array}$ & $\begin{array}{l}337 \\
(9)\end{array}$ & $\begin{array}{l}348 \\
/ 347 \\
(6 / 6)\end{array}$ & $\begin{array}{l}339 \\
(8)\end{array}$ & $\begin{array}{l}343 \\
(6)\end{array}$ & $\begin{array}{l}210 \\
/ \mathbf{2 0 3} \\
(0 / \mathbf{6})\end{array}$ & $\begin{array}{l}202 \\
(9)\end{array}$ & $\begin{array}{l}203 \\
(10)\end{array}$ & $\begin{array}{l}210 \\
/ \mathbf{1 6 4} \\
(1 / 11)\end{array}$ & $\begin{array}{l}189 \\
(10)\end{array}$ & $\begin{array}{l}188 \\
\text { (13) }\end{array}$ & $\begin{array}{l}234 \\
/ 230 \\
(6 / 9)\end{array}$ & $\begin{array}{l}231 \\
(15)\end{array}$ & $\begin{array}{l}224 \\
(14)\end{array}$ & $\begin{array}{l}227 \\
/ \mathbf{1 8 7} \\
(6 / 12)\end{array}$ & $\begin{array}{l}213 \\
(9)\end{array}$ & $\begin{array}{l}203 \\
(15)\end{array}$ \\
\hline
\end{tabular}

duration is usually three to four weeks longer, depending on the ice season, on GBL compared to GSL. These results add to our knowledge of ice phenology on the two lakes which had not been fully documented and contrasted in previous investigations.

Results from an initial comparison between AMSR-E estimated ice phenology variables and those estimated by QuikSCAT, as well as those obtained from NOAA IMS and CIS show that relatively coarse resolution AMSR-E 18.7 GHz H-pol $T_{\mathrm{B}}$ data are suitable for monitoring of ice phenology on the two lakes, at least in their main basins in a consistent manner. The ice phenology algorithm described in this paper may be applicable to other large lakes of the Northern Hemisphere and also to longer time series of passive microwave satellite data from SMMR-SSM/I (circa 32year historical record). Furthermore, there is likely the potential to estimate ice concentration during freeze-up and breakup from AMSR-E measurements. These are three lines of research that we are actively pursuing.
Acknowledgements. This research was supported by a NSERC Discovery Grant to C. Duguay. The AMSR-E/Aqua level 2A (AE_L2A) and IMS daily Northern Hemisphere snow and ice analysis data products were obtained from the National Snow and Ice Data Center Distributed Active Archive Center (NSIDC DAAC), University of Colorado at Boulder. Weekly ice cover fraction data was provided by the Canadian Ice Service (CIS). We would like to thank the anonymous reviewers for their constructive comments and suggestions which helped improve the original manuscript.

Edited by: A. Klein 


\section{References}

Barry, R. G. and Maslanik, J. A.: Monitoring lake freeze-up/breakup as a climatic index, in: Snow Watch '92, Detection strategies for snow and ice, World Data Center for Glaciology Report GD25, edited by: Barry, R. G., Goodison, B. E., and LeDrew, E. F., NSIDC: Boulder CO, 66-77, 1993.

Blanken, P., Rouse, W., and Schertzer, W. M.: Time scales of evaporation from Great Slave Lake: Cold Region Atmospheric and Hydrologic Studies: The Mackenzie GEWEX Experience Volume 2: Hydrologic Processes, edited by: Woo, M.-K., Springer, 181-196, 2008.

Bonsal, B. R., Prowse, T. D., Duguay, C. R., and Lacroix, M. P.: Impacts of large-scale teleconnections on freshwater-ice duration over Canada, J. of Hydrol., 330, 340-353, 2006.

Brown, L. C. and Duguay C. R.: The response and role of ice cover in lake-climate interactions, Prog. Phys. Geog., 34, 671704, doi:10.1177/0309133310375653, 2010.

Chang, A. T. C., Foster, J. L., Hall, D. K., Goodison, B. E., Walker, A. E., Metcalfe, J. R., and Harby, A.: Snow parameters derived from microwave measurements during the BOREAS winter field campaign, J. Geophys. Res., 102, 29663-29671, 1997.

Duguay, C. R., Flato, G. M., Jeffries, M. O., Ménard, P., Morris, K., and Rouse, W. R.: Ice-cover variability on shallow lakes at high latitudes: model simulations and observations, Hydrol. Process., 17, 3465-3483, 2003.

Duguay, C. R., Prowse, T. D., Bonsal, B. R., Brown, R. D., Lacroix, M. P., and Ménard, P.: Recent trends in Canadian lake ice cover, Hydrol. Process., 20, 781-801, 2006.

Helfrich, S. R., McNamara, D., Ramsay, B. H., Baldwin, T., and Kasheta, T.: Enhancements to, and forthcoming developments in the Interactive Multisensor Snow and Ice Mapping System (IMS), Hydrol. Process., 21, 1576-1586, 2007.

Hewison, T. J.: Airborne measurements of forest and agricultural land surface emissivity at millimeter wavelengths, IEEE Trans. Geosci. Remote Sens., 39, 393-400, 2001.

Hewison, T. J. and English, S. J.: Airborne retrievals of snow and ice surface emissivity at millimeter wavelengths, IEEE Trans. Geosci. Remote Sens., 37, 1871-1879, 1999.

Howell, S. E. L., Brown, L. C., Kang, K. K., and Duguay C. R.: Variability in ice phenology on Great Bear Lake and Great Slave Lake, Northwest Territories, Canada, from SeaWinds/QuikSCAT: 2000-2006, Remote Sens. Environ., 113, 816-834, 2009.

Jeffries, M. O. and Morris, K.: Some aspects of ice phenology on ponds in central Alaska, USA, Ann. Glaciol., 46, 397-403, 2007.

Jeffries, M. O., Morris, K., and Kozlenko, N.: Ice characteristics and processes, and remote sensing of frozen rivers and lakes in remote sensing in northern hydrology: Measuring environmental change, edited by: Duguay, C. R. and Pietroniro, A., Geophysical Monograph 163, American Geophysical Union, 63-90. 2005.

Kang, K.-K., Duguay, C. R., Howell, S. E. L., Derksen, C. P., and Kelly, R. J.: Seasonal evolution of lake ice thickness in Great Bear and Great Slave Lakes from AMSR-E, IEEE Geosci. Remote Sens. Lett., 7, 751-755, 2010.

Kelly, R. E. J.: The AMSR-E snow depth algorithm: Description and initial results, J. Remote Sens. Soc. Japan, 29, 307-317, 2009.
IGOS: Integrated Global Observing Strategy Cryosphere Theme Report, WMO/TD-No. 1405, World Meteorological Organization, Geneva, 100 pp, 2007.

Kouraev, A. V., Semovski, S. V., Shimaraev, M. N., Mognard, N. M., Légresy, B., and Remy, F.: Observations of Lake Baikal ice from satellite altimetry and radiometry, Remote Sens. Environ., 108, 240-253, doi:10.1016/j.rse.2006.11.010, 2007.

Latifovic, R. and Pouliot, D.: Analysis of climate change impacts on lake ice phenology in Canada using the historical satellite data record, Remote Sens. Environ., 106, 492-508, 2007.

Magnuson, J. J., Robertson, D. M., Benson, B. J., Wynne, R. H., Livingstone, D. M., Arai, T., Assel, R. A., Barry, R. G., Card, V., Kuusisto, E., Granin, N. G., Prowse, T. D., Stewart, K. M., and Vuglinski, V. S.: Historical trends in lake and river ice cover in the northern hemisphere, Science, 289, 1743-1746, doi:10.1126/science.289.5485.1743, 2000.

Maslanik, J. A. and Barry, R. G.: Lake Ice Formation and Breakup as an Indicator of Climate Change: Potential for Monitoring Using Remote Sensing Techniques, The Influence of Climate Change and Climatic Variability on the Hydrologic Regime and Water Resources, International Association of Hydrological Sciences Press, IAHS Publ. No. 168, 153-161, 1987.

Rouse, W. R., Binyamin, J., Blanken, P. D., Bussières, N., Duguay, C. R., Oswald, C. J., Schertzer, W. M., and Spence, C.: The Influence of Lakes on the Regional Energy and Water Balance of the Central Mackenzie River Basin, Cold Region Atmospheric and Hydrologic Studies: The Mackenzie GEWEX Experience Volume 1: Atmospheric Processes, edited by: Woo, M.-K., Springer, 309-325, 2008a.

Rouse, W. R., Blanken, P. D., Bussières, N., Oswald, C. J., Schertzer, W. M., Spence, C., and Walker, A. E.: An Investigation of the Thermal and Energy Balance Regimes of Great Slave and Great Bear Lakes, J. Hydrom., 9, 1318-1333, 2008b.

Schertzer, W. M, Rouse, W. R., Blanken, P. D., Walker, A. E., Lam, D. C. L., and León, L.: Interannual Variability of the Thermal Components and Bulk Heat Exchange of Great Slave Lake, Cold Region Atmospheric and Hydrologic Studies: The Mackenzie GEWEX Experience Volume 2: Hydrol. Process., edited by: Woo, M.-K., Springer, 197-219, 2008.

Ulaby, F. T., Moore, R. E., and Fung, A. K.: Microwave remote sensing: active and passive, Vols. 1, 2 and 3, Addison-Wesley Publishing Company, MA, 1986.

Walker, A. E. and Davey, M. R.: Observation of Great Slave Lake ice freeze-up and break-up processes using passive microwave satellite data, Proceedings of $16^{\text {th }}$ Symposium on Remote Sensing, Sherbrooke, QC, Canada, L'AQT/CRSS, 233-238, 1993.

Walker, A. E., Silis, A., Metcalf, J. R., Davey, M. R., Brown, R. D., and Goodison B. E.: Snow cover and lake ice determination in the MAGS region using passive microwave satellite and conventional data, Proc. 5th Scientific Workshop, Mackenzie GEWEX Study, Edmonton, Alberta, Canada, 39-42, 2000.

Woo, M. K., Rouse, W. R., Stewart, R. E., and Stone, J. M. R.: The Mackenzie GEWEX Study: A contribution of cold region atmospheric and hydrologic sciences, Cold Region Atmospheric and Hydrologic Studies: The Mackenzie GEWEX Experience Volume 1: Atmospheric Processes, edited by: Woo, M.-K., Springer, 181-196, 2008. 